تأثير شرايط رطوبتى و غلظت آمونيوم بر نيتراتسازى در دو خاك با بافت متفاوت

رويا دارابى كندلجى، شاهين اوستان*، ناصر على اصغرزاد و نصرتاله نجفى'

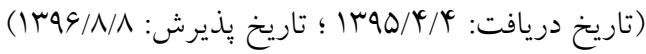

جكيده

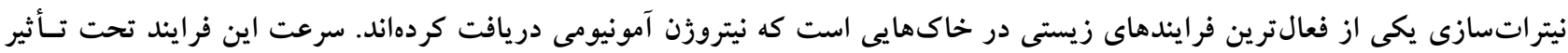

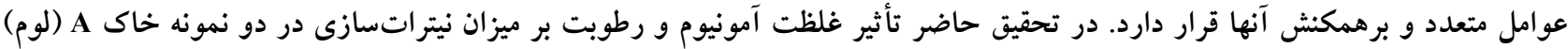

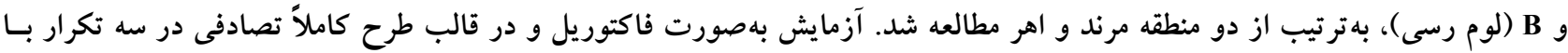

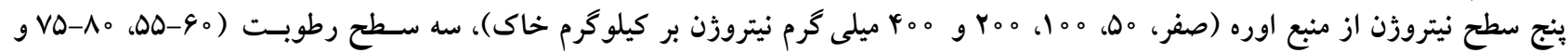

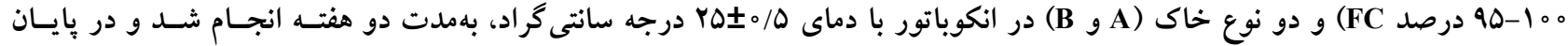

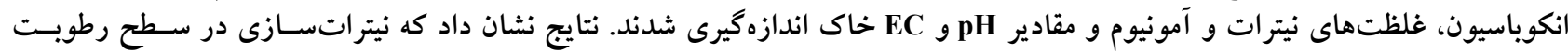

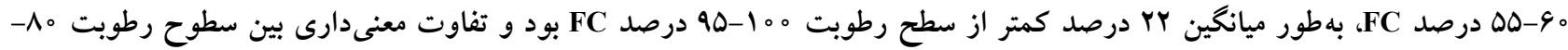

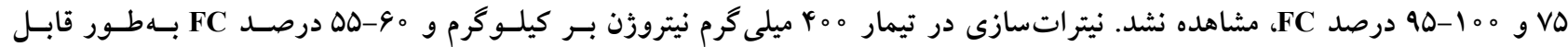

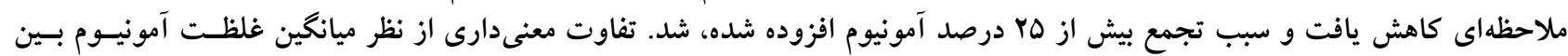

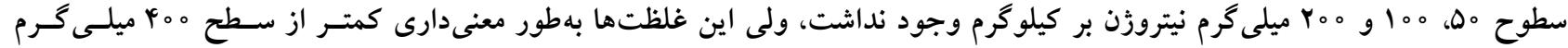

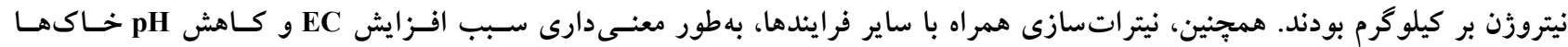

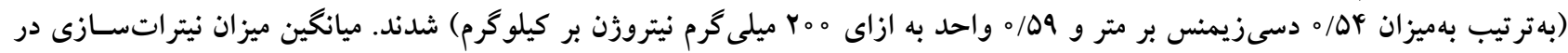

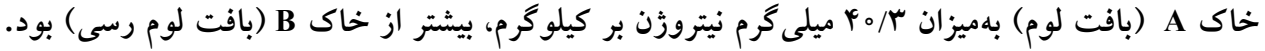

وازههاى كليدى: اوره، رطوبت خاك، نيتراتسازى، EC، 


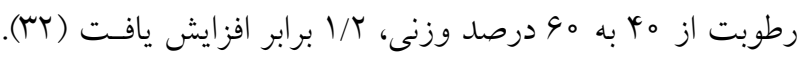

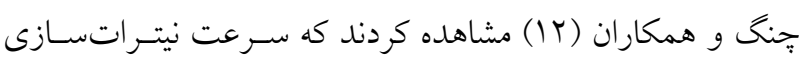

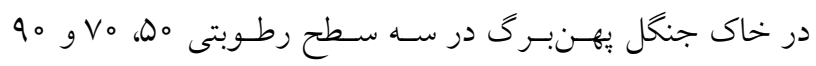

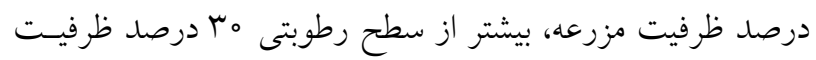

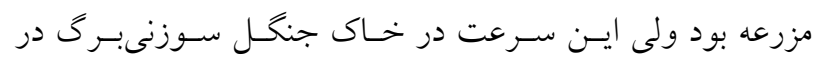

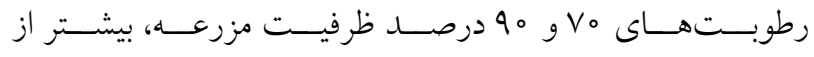

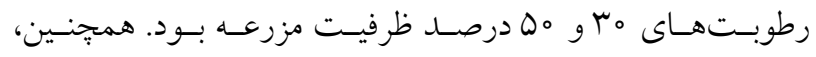

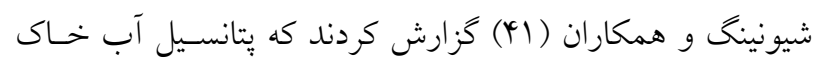

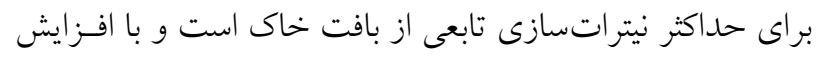

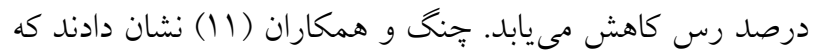
تأثير رطوبت خاك بر نيتراتسازى تابع نوع كاربرى زمهين اسـت فئ.

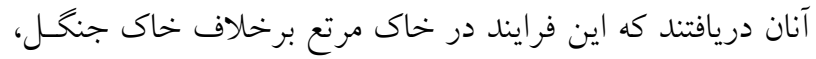

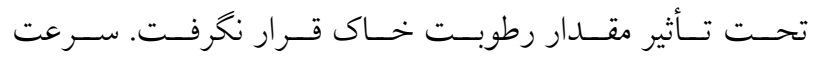

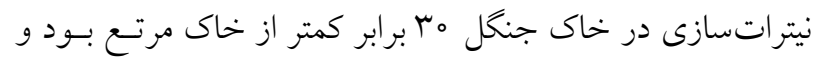

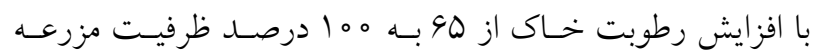

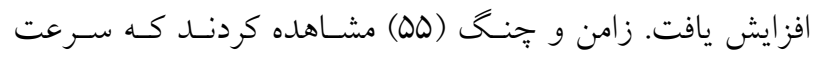

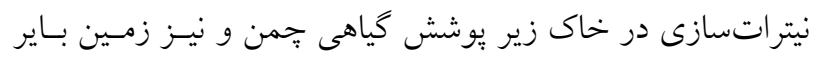

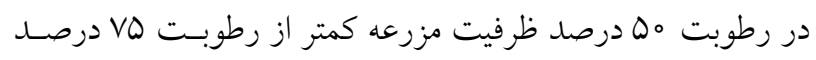

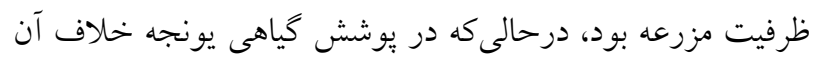

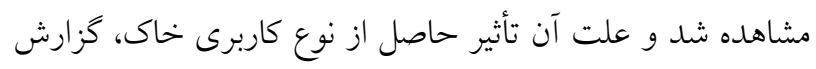

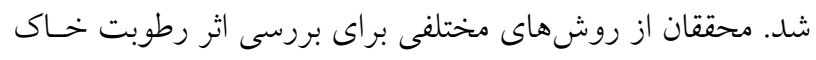

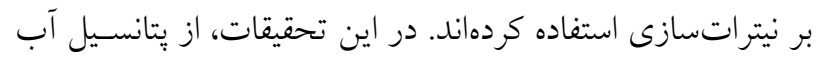

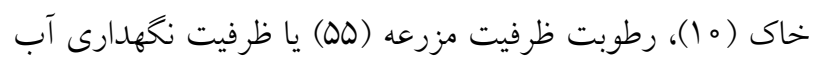

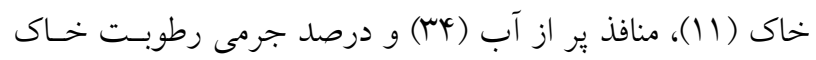

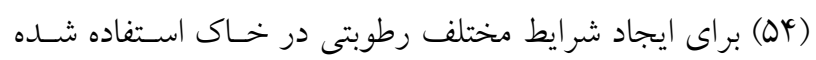

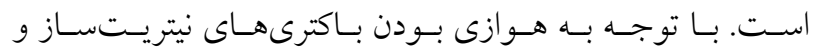

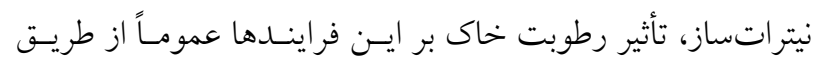

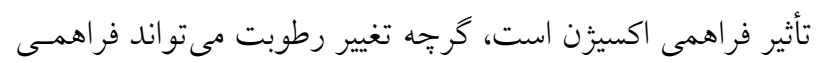

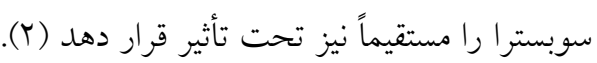
تحقيقات انجامكرفته در زمينه عوامل مؤثر بر نيتـراتسـازى

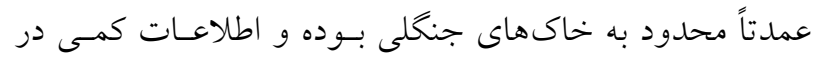

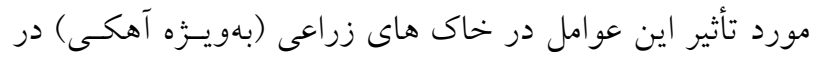

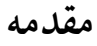
نيتراتسـازى تبـــيل بيولوزيـك آمونيـاك (NH

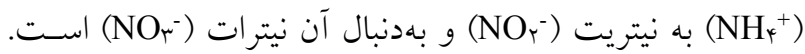

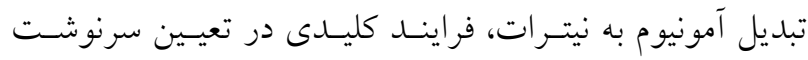

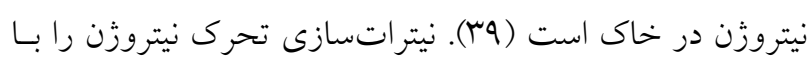

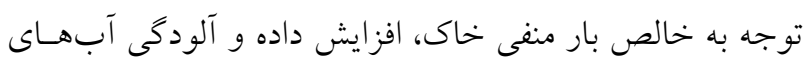

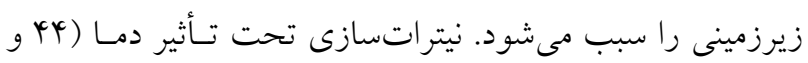

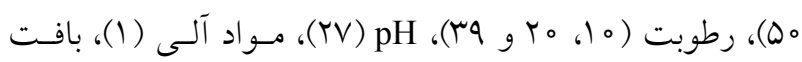

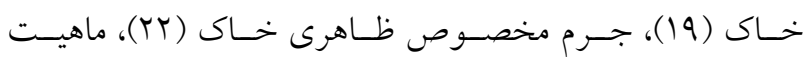

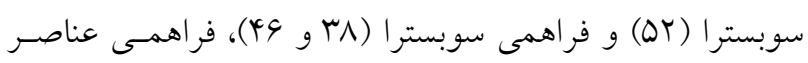

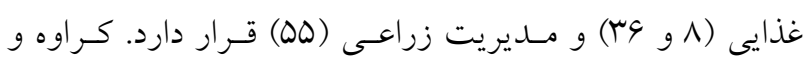

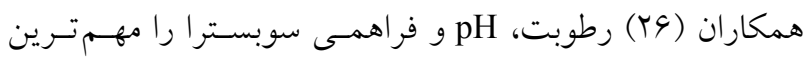

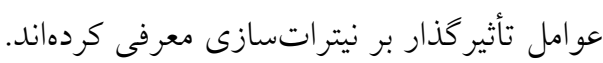

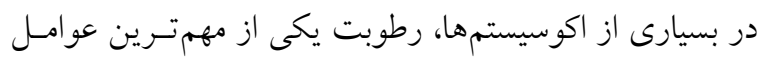

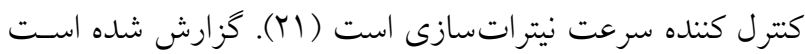

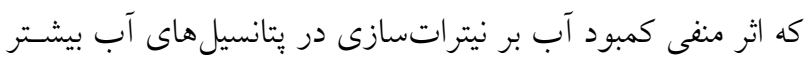

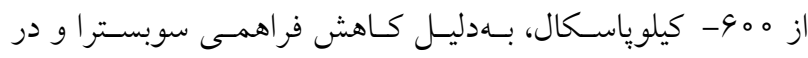

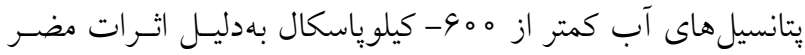

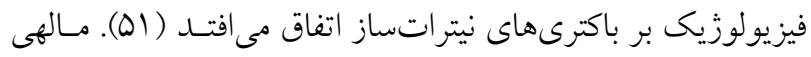

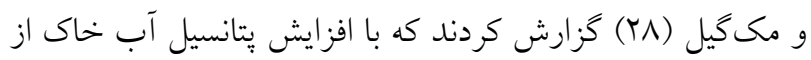

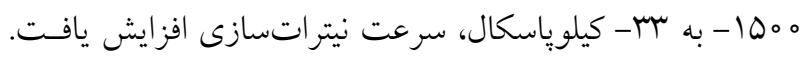

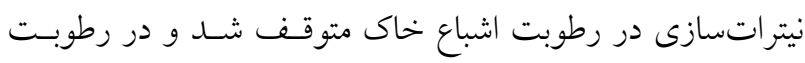

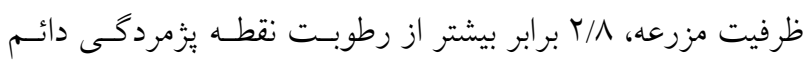

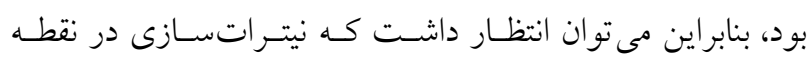

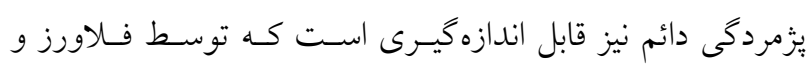

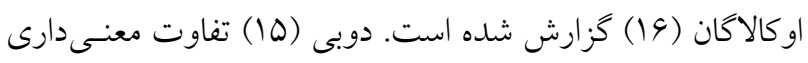

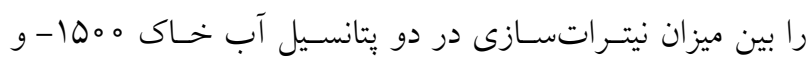

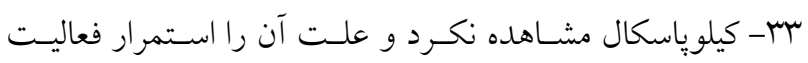

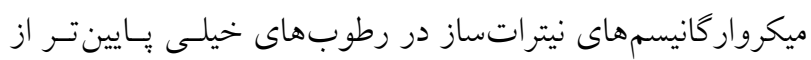

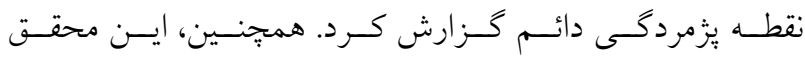

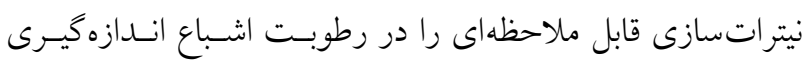
كرد. همجنين، سرعت نيتراتسازى در يكى خاك با افزايش مقدار 


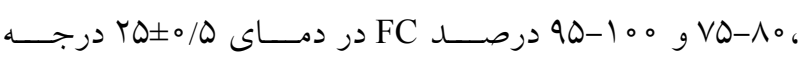
سلسيوس انكوباتور بهمدت دو هفتـه انكوبـهـ شــند. نمونـهـهـا بهصورت روزانه توزين و در صورت لزوم با اضـافه كـردن آب

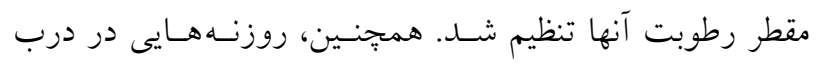

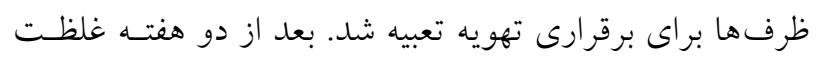

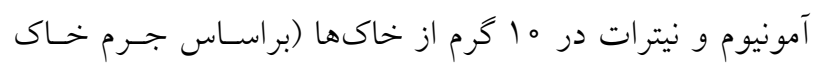
خشك) به روش بلك و وارينـ (4) بـا عصـارهذيـر سـولفات

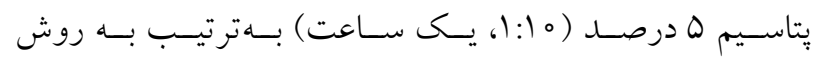

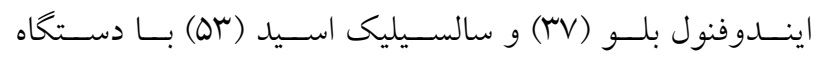

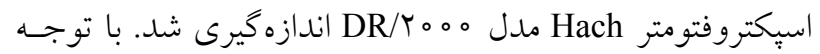
به عدم استفاده از مهاركنندههاى مصرف نيتـرات، آنجـهـ در ايسن تحقيق مورد اندازه گيرى قرار گرفت، نيتراتسازى ناخالص بـود

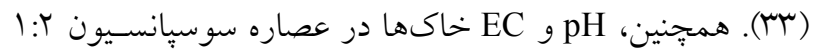
خاى و آب مقطر اندازهيرى شدند. نرخ نيتراتسـازى برحسـب درصــ توليــ نيتـرات در روز

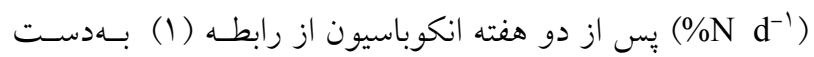

$\% \mathrm{Nd}^{-1}=\frac{(\mathrm{A}-\mathrm{B}) \times 100}{(\mathrm{~S}+\mathrm{NA}) \times \mathrm{n}}$

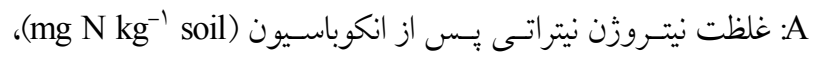
غلظت اولئُ نيتروزن نيتراتى (mg N kg-1 soil)، S: غلظت نيتـروزن

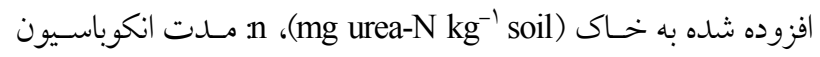
(روز)، NA: فاكتور تصحيح براى آمونياكسازى و آلى شـدن در طى بـ انكوباسيون كه از رابطه (Y) بهدست آمل:

$\mathrm{NA}=\mathrm{C}-[\mathrm{S}+\mathrm{D}]$

$\mathrm{NH}^{+}-\mathrm{N}$ غجمون : غلظت نيتروزن معدنى بس از انكوباسيون (C و NOr-N برحسب Dg N kg soil)، غلظت اولية نيتـروزن

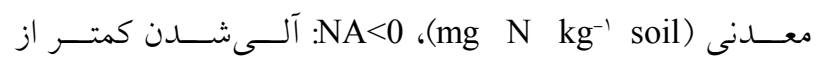
آمونياكسازى است، NA>0: آلى شدن نامتحرى سازى بيشـتر از آمونياكسازى است.

آزمايش به صورت فاكتوريل و در قالب طرح كـاملاً تصـادفى در سه تكرار و با فاكتور نيتروزن از منبع اوره در ينج سطح (صفر،

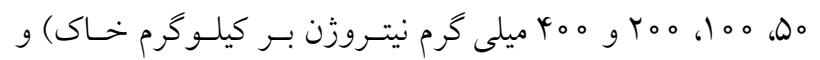

دست است. در اين تحقيق تأثير توأم سطوح رطوبت خـاك بـر مبناى كسرى از ظرفيت مزرعه و غلظت آمونيوم از منبع اوره بر ميزان نيتراتسازى در دو خاك با بافت متفـاوت مـورد بررسى هـ

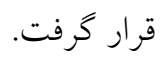

\section{مواد و روشها}

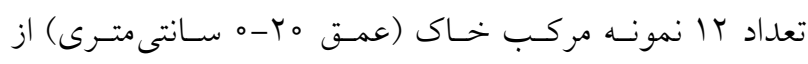
اراضى زراعى شهرستانهاى اهر و مرند با حداقل بهممخـوردكى نمونهبردارى شدند. نمونهها بهميزان حدود ه ا كيلوگرم يسس از انتقال به آزمايشگاه و عبور ملايم از الك دو ميلى مترى تا يايسان

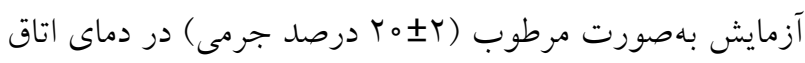

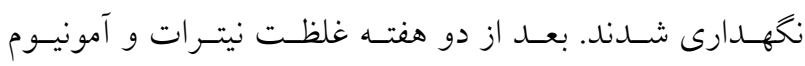
خاكها به روشهايى كه در ادامه ذكر خواهند شد، اندازهيـرى شد. از بين rا نمونه خاك، دو نمونه خاك متوسط بافت منطقـه

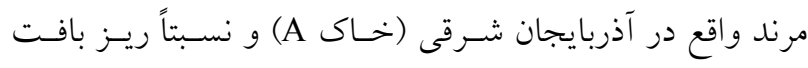
منطقه اهر واقع در آذربايجان غربى (خاى B) با حداقل غلظـت نيترات براى انجام آزمايشها بعدى انتخاب شــند (YY). مقـدار معينى از هر دو خاك هو اخشك شده و بعد از نرم كردن و عبور از الك دو ميلى مترى ويزگى هاى فيزيكى و شيميايى آنها شـامل

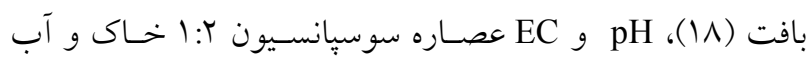
مقطر (IV)، درصد كربن آلى (I/)، درصد كربنات كلسيم معادل (ه)، ظرفيت تبادل كاتيونى (9)، رطوبت ظرفيت مزرعه به روش كلدانى (YY) اندازه گيرى شدند.

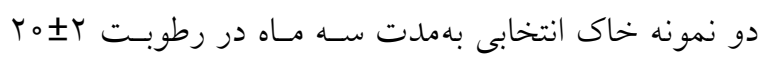
درصد جرمى بهمنظور نزديك شدن به حالت تعـادل بيولوزيـى نخهدارى شدند (Y). دو هفته قبل از افزودن نيتروزن به خاكها،

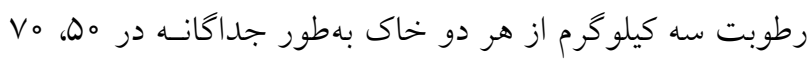

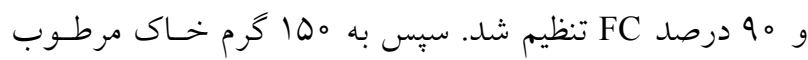

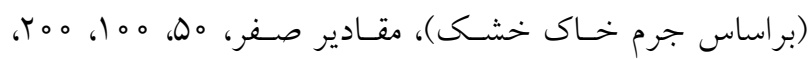

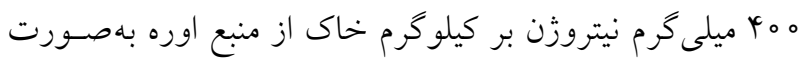

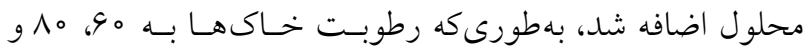
ه م درصد FC برسد. خاكهـا در سـه تيمـار رطـوبتى 09-9ها 
بهدلايلى كاهش مى يافت، تجمـع آمونيـوم صـورت مسى كرفـت (YO)

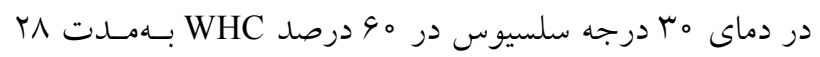

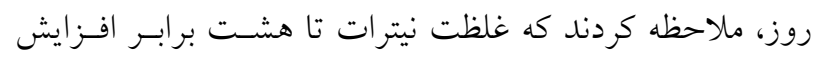

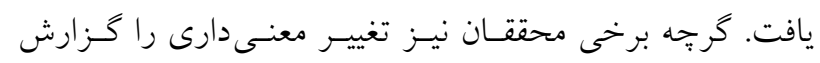

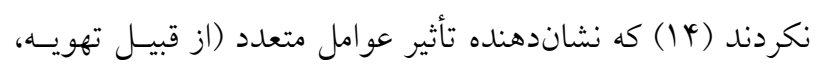

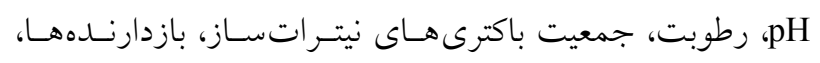

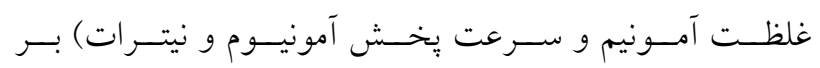
نيتراتسازى در خاى است (Yo).

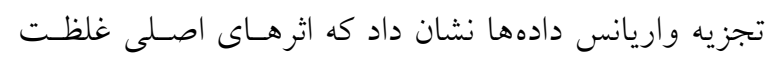

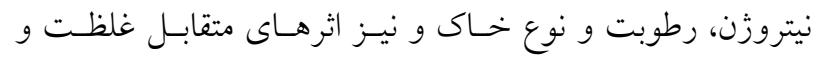

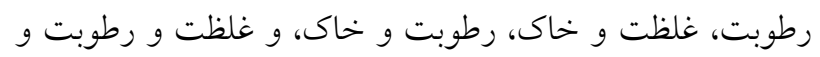

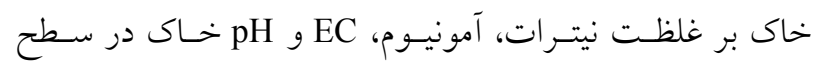

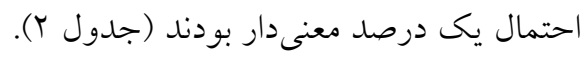

\section{نيترات}

مقايسه ميانخين ها نشـان داد كـه غلظـت نيتـرات در تيمارهـاى

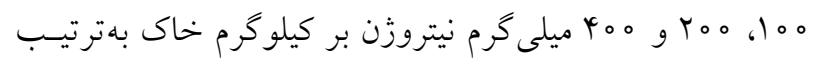

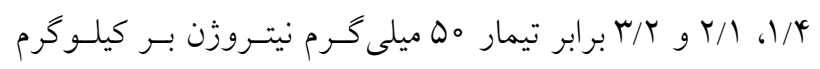

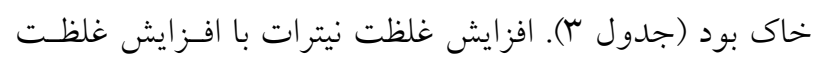

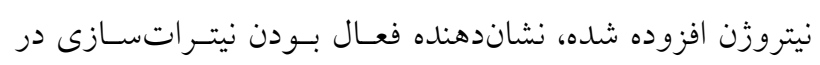

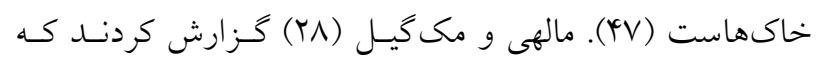

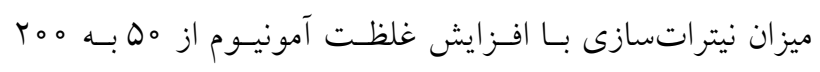

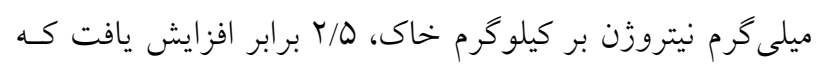

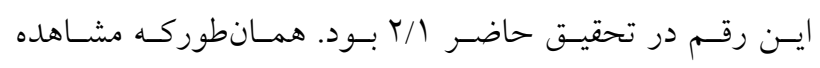

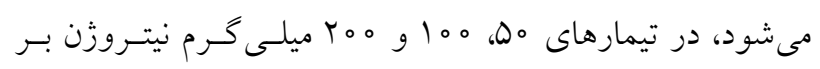

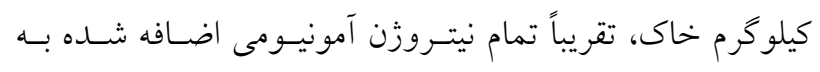

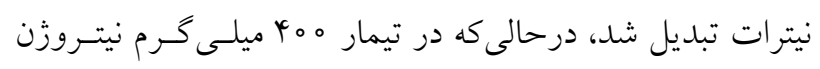

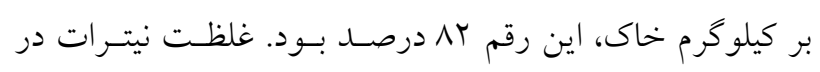

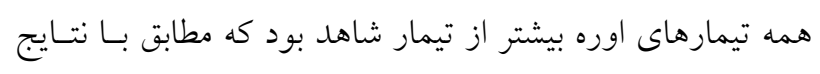

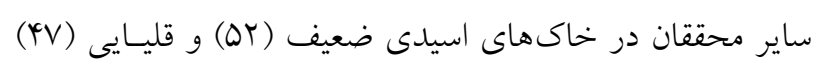

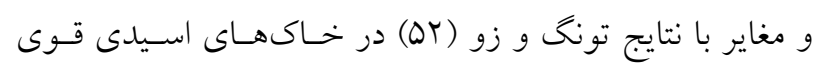

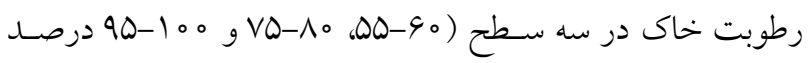
(FC

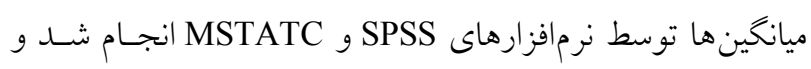

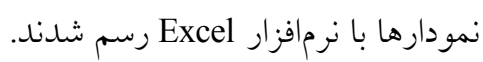

\section{نتاج و بحث}

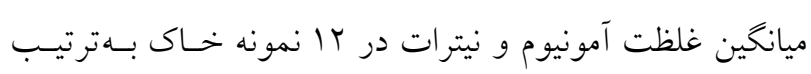
س/

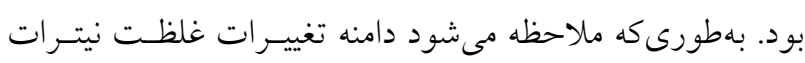

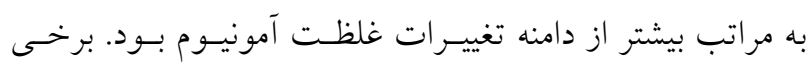

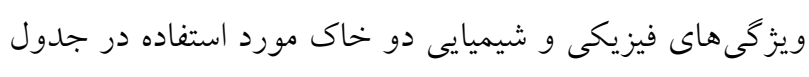

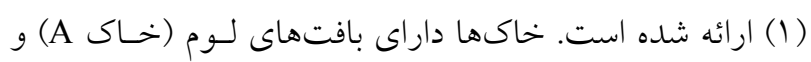

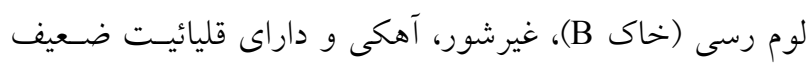

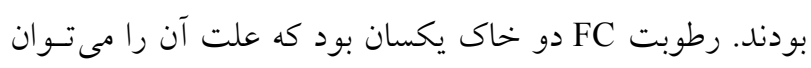

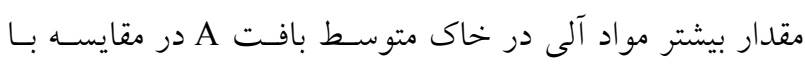

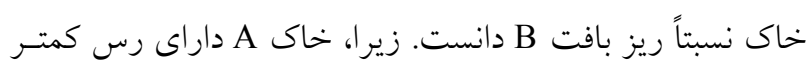

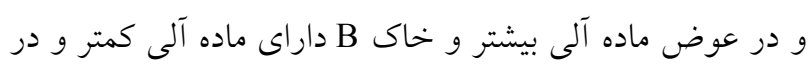

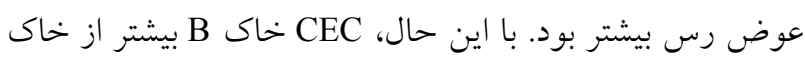

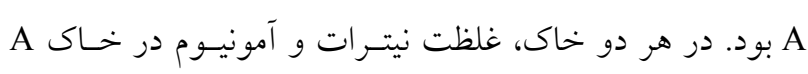

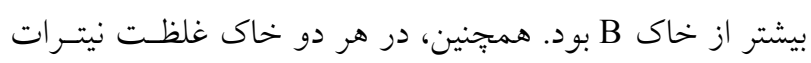
كمتر از آمونيوم بود.

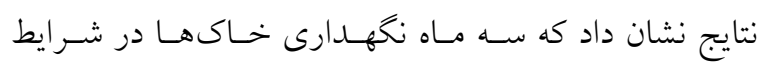
مرطوب باعث افزايش غلظت نيترات و كاهش غلظـت آمونيـوم

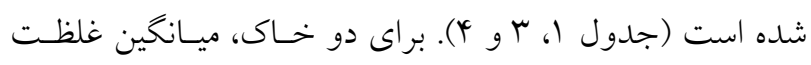

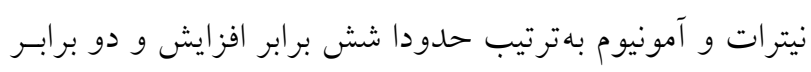

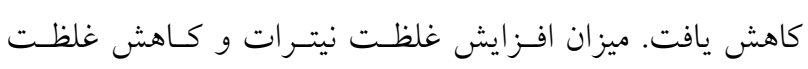

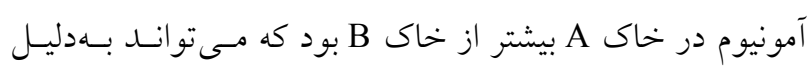

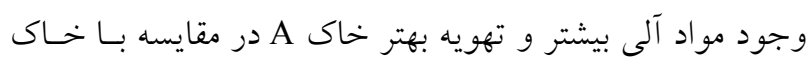

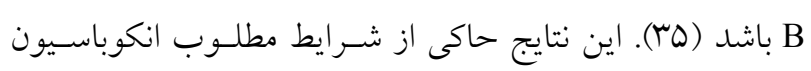

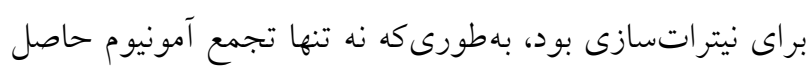

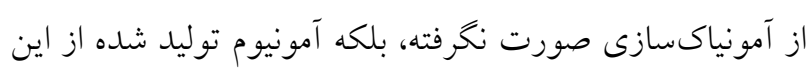

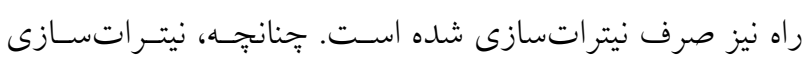




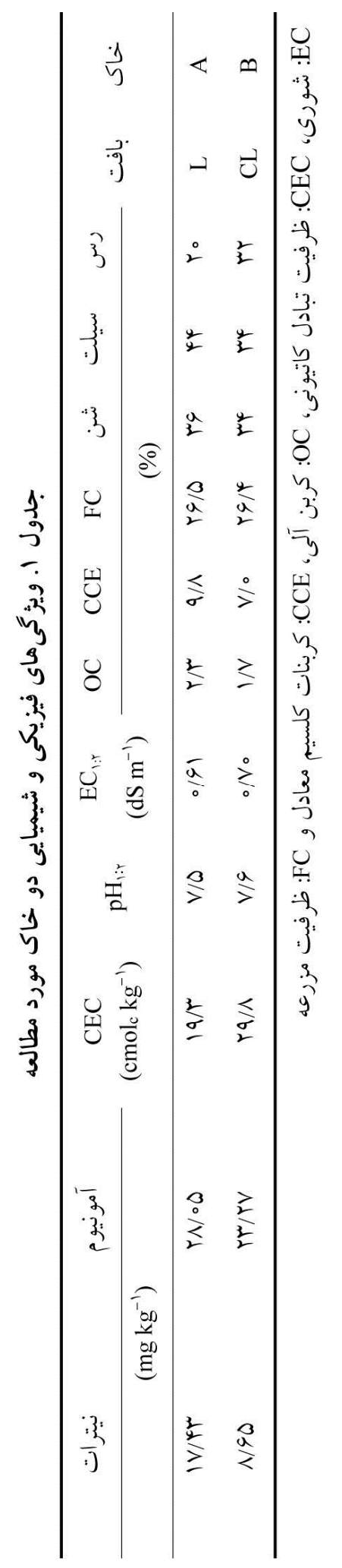


جدول r. نتايج تجزيه واريانس اثر نيتروزن، رطويت و نوع خاك بر غلظتهاى نيترات و آمونيوم، PH و EC

\begin{tabular}{|c|c|c|c|c|c|}
\hline \multicolumn{4}{|c|}{ ميانكين مربعات } & \multirow{2}{*}{ درازجه } & \multirow{2}{*}{ منابع تغييرات } \\
\hline $\mathrm{pH}$ & $\mathrm{EC}$ & آمونيوم & 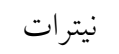 & & \\
\hline $1 / 9 \circ 9^{* *}$ & $Y / \backslash Q Y^{* *}$ & 每 & $1 /\left.4 \Delta\right|^{* * *}$ & $r$ & نيتروزن \\
\hline$\circ / 1 \circ \mu^{* *}$ & $\circ / 19 \mu^{* * *}$ & MI99/9** & $0 / 119^{* *}$ & r & رطوبت \\
\hline$\circ / 019^{n s}$ & $\circ / 0 Y^{* *}$ & $V Y / q \circ Y^{\mathrm{ns}}$ & $0 / T 99^{* *}$ & 1 & نوع خاى \\
\hline$\circ / \circ V Y^{* *}$ & $\circ / \circ \circ \varsigma^{* *}$ & $r V r q / q^{* *}$ & $\circ / \circ \circ 9^{* *}$ & $\wedge$ & نيتروزن × رطوبت \\
\hline$\circ / \circ \varphi^{* *}$ & $\circ / \circ \circ V^{* *}$ & $\mid \mu r / v \circ * *$ & $0 /\left.01\right|^{* *}$ & 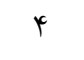 & نيتروزن × نوع خاك \\
\hline$\circ / T V^{* *}$ & $\circ / \circ r^{* *}$ & $\Lambda \mu V / \Psi V^{* *}$ & $\circ / \circ \circ \varphi^{* *}$ & r & رطوبت × نوع خاى \\
\hline$\circ /\left.04\right|^{* *}$ & $\circ / \circ \circ \varphi^{* *}$ & $r \circ \varphi / T V^{* *}$ & $\circ / \circ \circ \Delta^{* *}$ & $\wedge$ & نيتروزن × رطوبت × نوع خاك \\
\hline $0 / 009$ & $0 / 001$ & 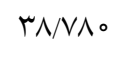 & $0 / 001$ & 90 & خطاى آزمايش \\
\hline $1 / \pi 1$ & $r / \mu 。$ & $r \varphi / \Lambda$ & $1 / 10$ & - & ضريب تغييرات (.٪) \\
\hline
\end{tabular}

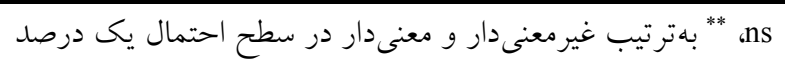

جدول r. مقايسه ميانخينهاى مربوط به اثرهاى اصلى نيتروزن، رطوبت و نوع خاك بر غلظتهاى نيترات و آمونيوم، pH و EC

\begin{tabular}{|c|c|c|c|c|c|}
\hline \multirow{2}{*}{$\mathrm{pH}$} & \multirow{2}{*}{$\begin{array}{c}\mathrm{EC} \\
\left(\mathrm{dS} \mathrm{m}^{-1}\right)\end{array}$} & آمونيوم & نيترات & سطح نيتروزن & \multirow{2}{*}{ اثر اصلى } \\
\hline & & \multicolumn{3}{|c|}{$\left(\mathrm{mg} \mathrm{kg}^{-1}\right)$} & \\
\hline$V / V Y^{\mathrm{ca}}$ & $\circ / 99$ re & $11 /\left.9\right|^{\mathrm{c}}$ & $V / T V^{e}$ & صفر & \multirow{5}{*}{ نيتروزن } \\
\hline$V / D)^{c b}$ & o/AYYd & $\mid \Lambda / 4 \Lambda^{b}$ & $\mid r V / 0^{d}$ & Q. & \\
\hline$V / \pi \mu^{c}$ & $\circ / 919^{\circ}$ & $19 / \pi \wedge^{b}$ & $\operatorname{lV} g / \mu^{\mathrm{c}}$ & 100 & \\
\hline $\mathrm{V} / / Q^{\mathrm{d}}$ & $1 / \Gamma \wedge q^{b}$ & Yo/ ${ }^{c b}$ & $r q \mathrm{~V} / \Lambda^{\mathrm{b}}$ & roo & \\
\hline $\mathrm{V} / \mathrm{o}^{\circ} \mathrm{e}$ & $1 / V V \Lambda^{\mathrm{a}}$ & $49 / q^{a}$ & $Y \circ \Delta / D$ & Yoo & \\
\hline$V / Y I^{a}$ & $1 / \circ \mu^{\top c}$ & $\mu y / q l^{a}$ & $\mid V N /{ }^{4 b}$ & $\circ / \Delta \mathrm{DFC}-\circ / 9 \circ \mathrm{FC}$ & \multirow{3}{*}{ رطوبت } \\
\hline$V / r q^{\circ}$ & $1 / \circ 9 V^{b}$ & $19 / 79 \mathrm{~b}$ & TYY/G & $\circ / \mathrm{V} \Delta \mathrm{FC}-\circ / \wedge \cdot \mathrm{FC}$ & \\
\hline$V / \mu r b$ & $1 / Y Y_{\circ} a$ & $\mid Q / D \psi_{c}$ & $r T q / r$ & $\circ / 9 \Delta \mathrm{FC}-\mathrm{FC}$ & \\
\hline$V / r^{4}$ & $1 / 090$ & $Y Y / I Y$ & $r M \circ / 9$ & A & \multirow{2}{*}{ نوع خاى } \\
\hline$V / r y$ & $1 / 141$ & Tr/MY & $190 / 9$ & B & \\
\hline
\end{tabular}

* در هر ستون، ميانخين هاى داراى حداقل يك حرف مشترى، با آزمون دانكن و در سطح احتمال بنج درصد تفاوت معنى دارى ندارند.

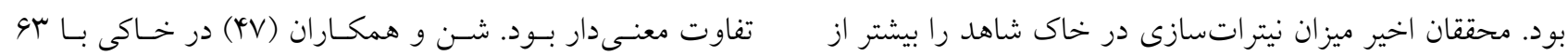

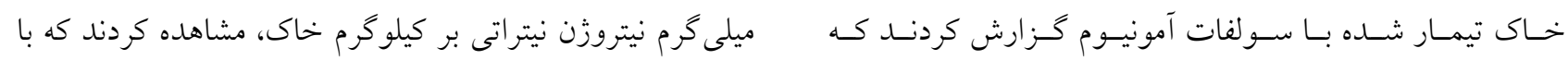

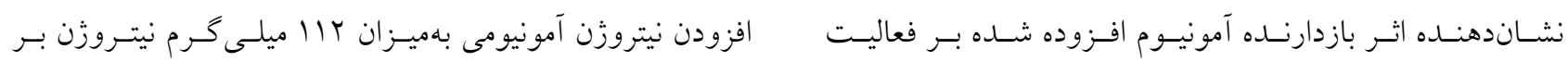

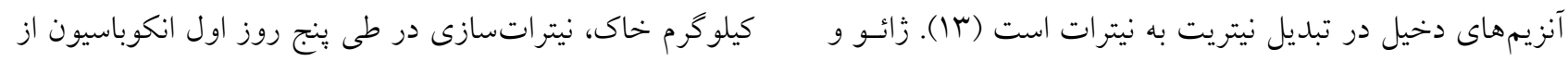

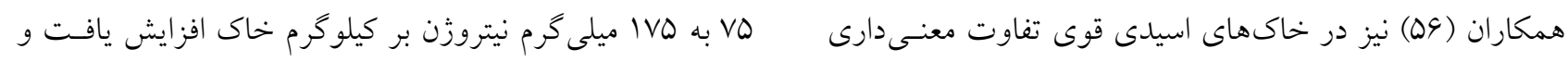

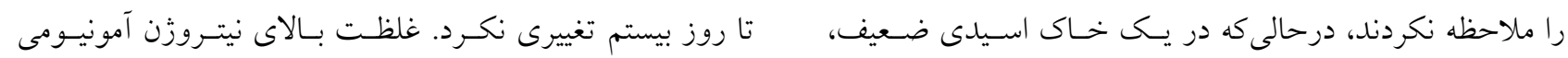




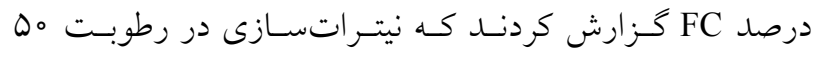

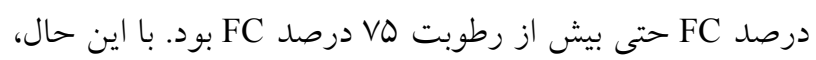

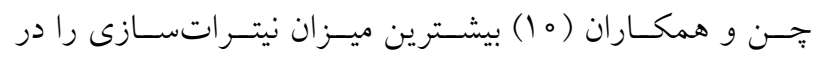

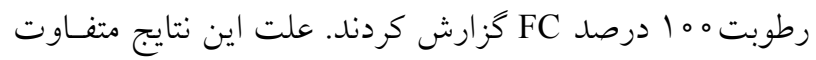

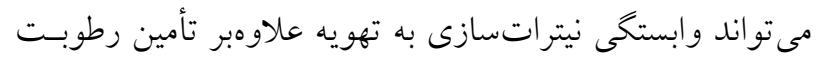

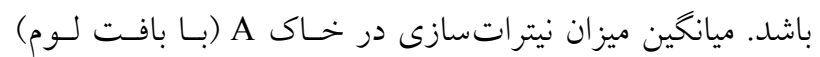

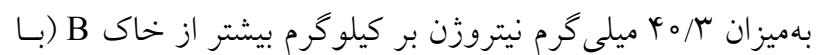

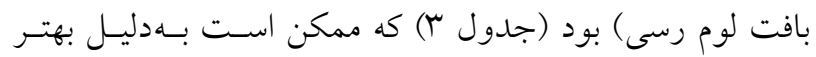
بودن شرايط تهويه در خاك A در مقايسه با خـاك B باشـــ. بـا

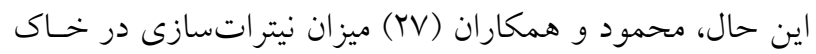

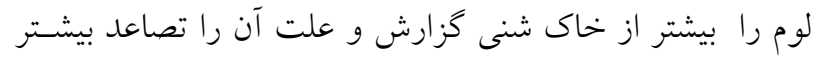

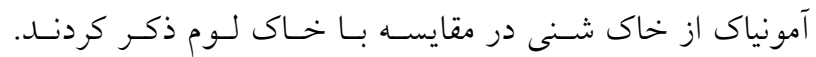
شيونينگ و همكاران (أ|) حداكثر نيتراتسازى براى خاكهاى

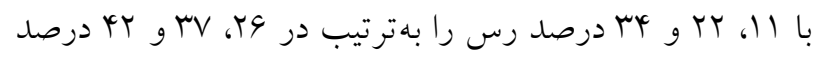

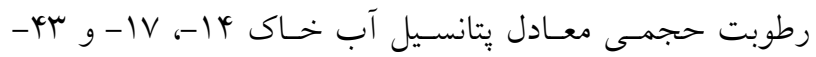

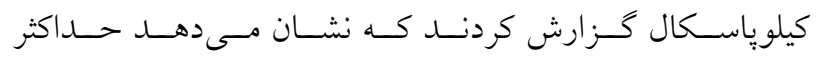

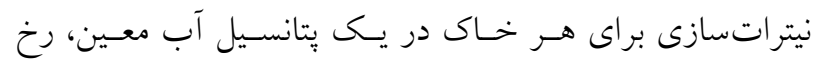
مى دهد. اثر متقابـل غلظـت نيتـروزن و رطوبـت نشـان داد كـه كـاهش

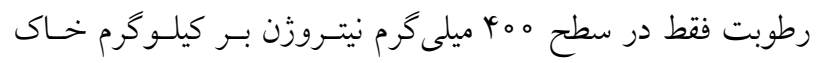

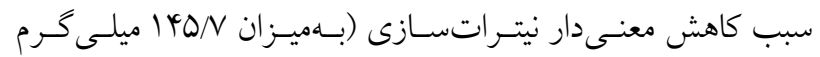

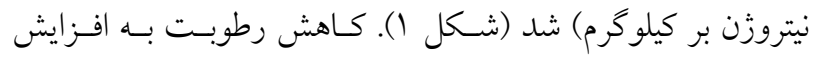

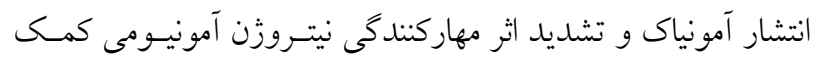

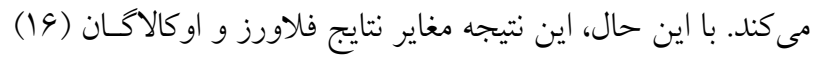
است كه مهار نيتراتسازى را مستقل از رطوبت و حتى دماى خاك

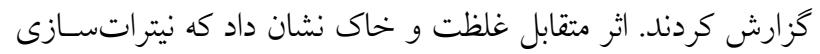

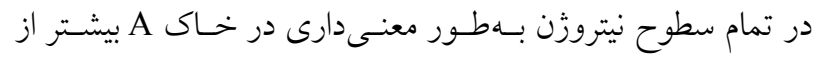
خاك B بود (شكل Y). اثر متقابل رطوبت و خاك نيز نشـان داد كـه

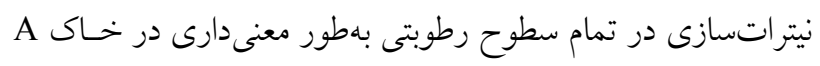

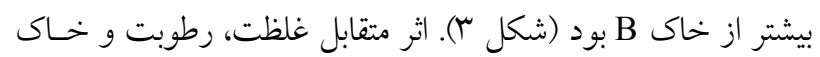

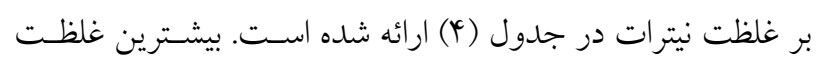

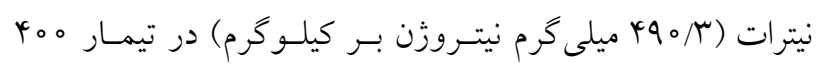

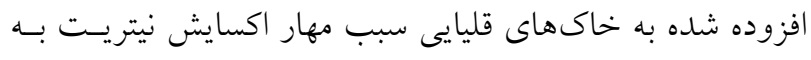

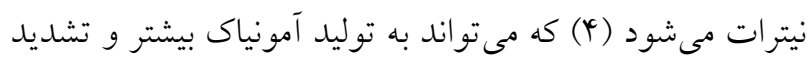

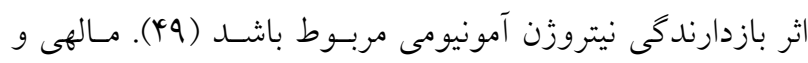

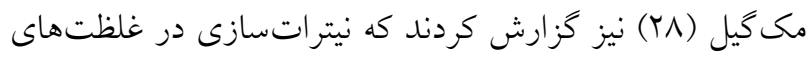

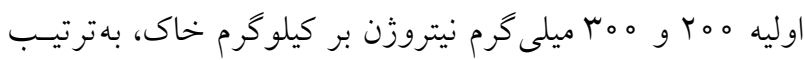

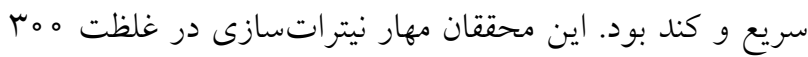

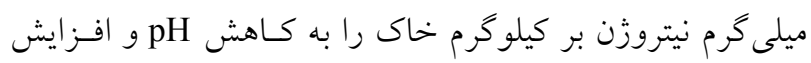

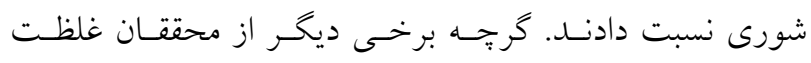

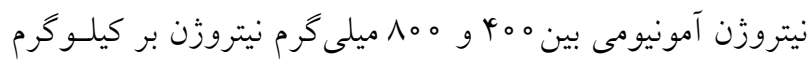

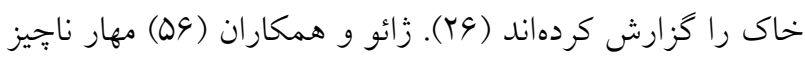

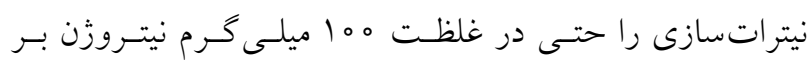

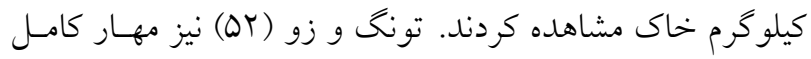

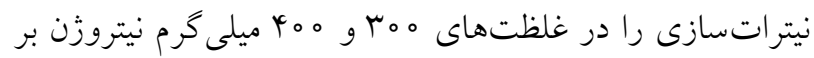

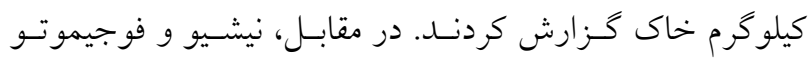

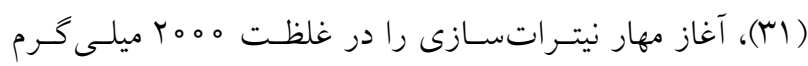

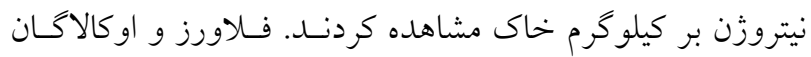

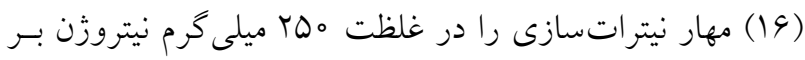
كيلو گرم خاى گزارش كردند.

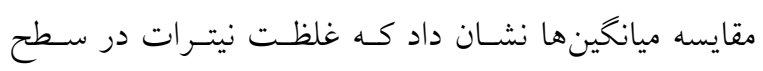

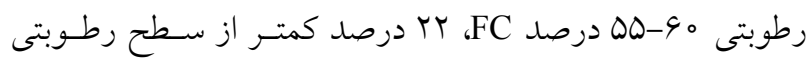

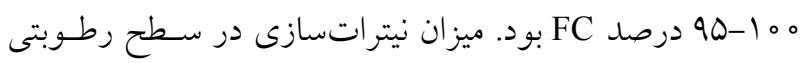

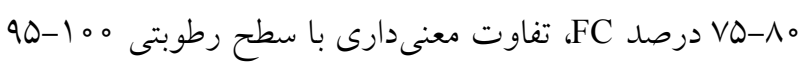

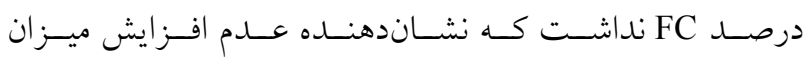

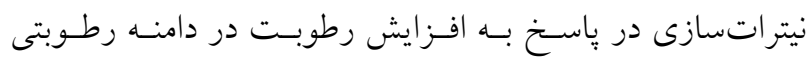

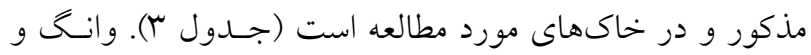

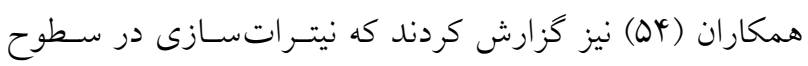

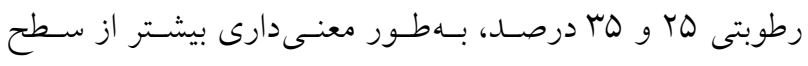

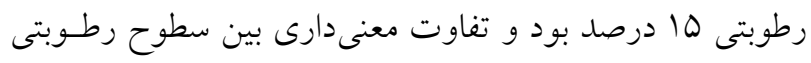

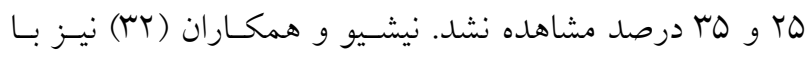

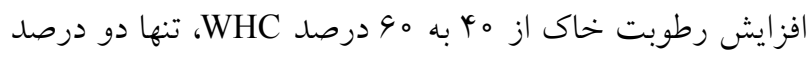

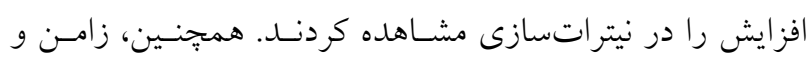

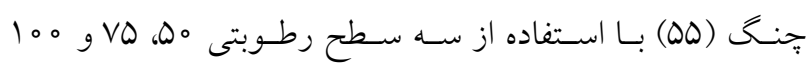




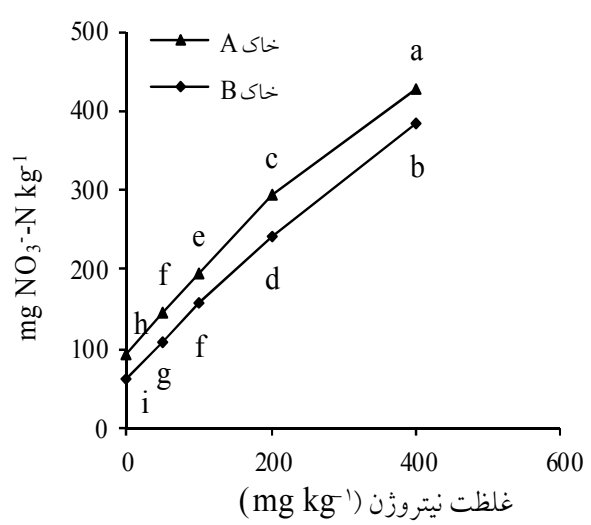

شكل r. اثر متقابل غلظت نيتروزن و نوع خاك بر غلظت نيترات ميانگينهاى داراى حداقل يك حرف مشتر ب با آزمون دانكن و در برد سطح احتمال بنج درصد تفاوت معنادارى ندارند.

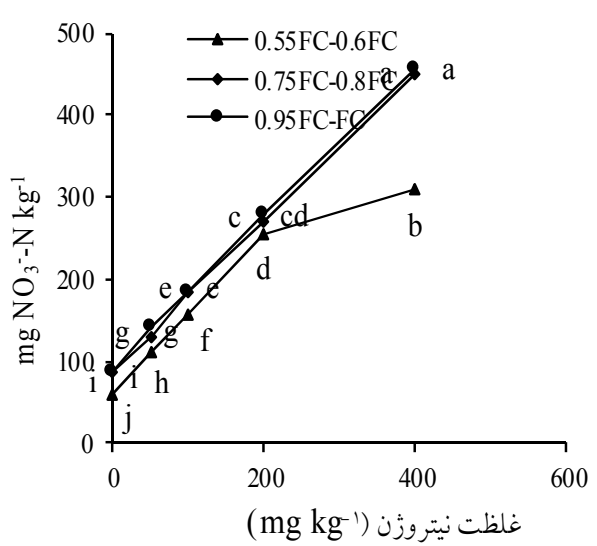

شكل ا. اثر متقابل غلظت نيتروزن و رطوبت بر غلظت نيترات

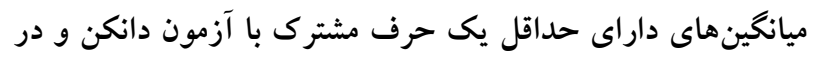
سطح احتمال ينج درصد تفاوت معنادارى ندارند.

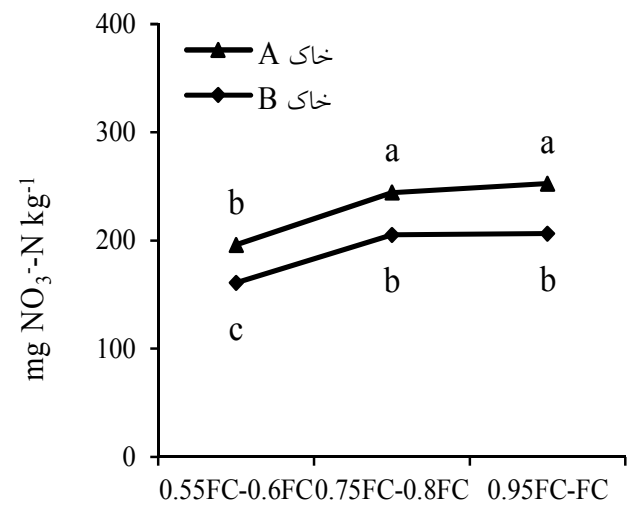

$$
\text { رطوبت خاى }
$$

شكل r. اثر متقابل رطوبت و نوع خاك بر غلظت نيترات. ميانخينهاى داراى حداقل يك حرف مشتر بـ باك

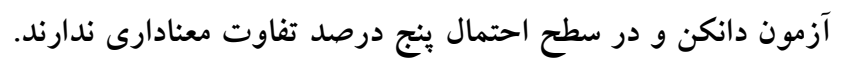

غلظت نيتروزن و رطوبت بر غلظت آمونيـوم در سـطح احتمـال

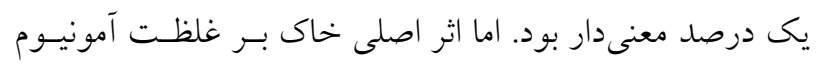

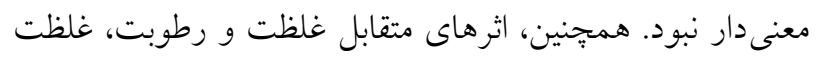

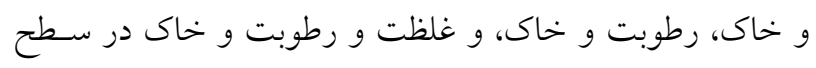
احتمال يك درصد معنى دار شدند.

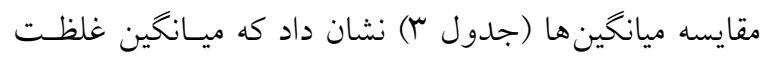

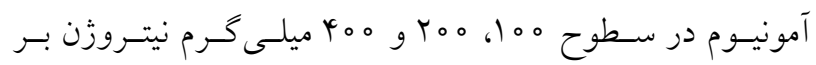

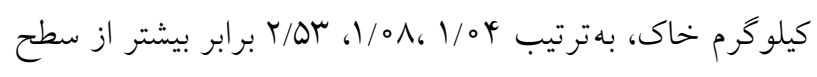

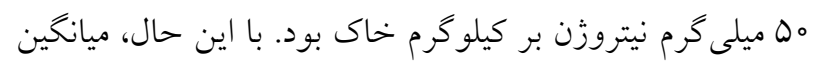

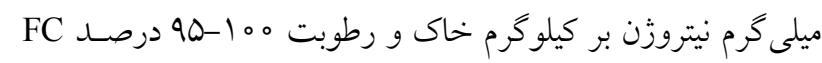

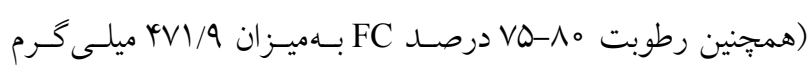

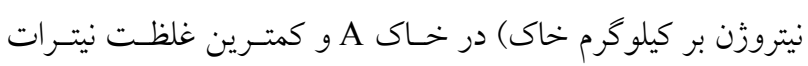

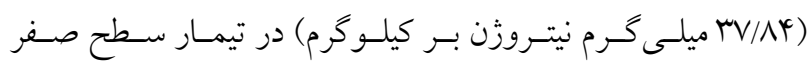

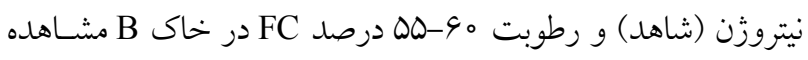

آمونيوم تجزيه واريانس دادهها (جدول r) نشـان داد كـه اثـرات اصـلى 
جدول Fا. مقايسه ميانگينهاى مربوط به اثرهاى متقابل نيتروزن، رطوبت و نوع خاك غلظتهاى نيترات و آمونيوم، pH و EC

\begin{tabular}{|c|c|c|c|c|c|c|}
\hline \multirow{2}{*}{$\mathrm{pH}$} & \multirow{2}{*}{$\begin{array}{c}\mathrm{EC} \\
\left(\mathrm{dS} \mathrm{\textrm {m } ^ { - 1 }}\right)\end{array}$} & آمونيوم & نيترات & \multirow{2}{*}{ نوع خاى } & \multirow{2}{*}{ رطوبت } & \multirow{2}{*}{$\begin{array}{c}\text { سطح نيتروزن } \\
\left(\mathrm{mg} \mathrm{kg}^{-1}\right)\end{array}$} \\
\hline & & \multicolumn{2}{|c|}{$\left(\mathrm{mg} \mathrm{kg}^{-1}\right)$} & & & \\
\hline V/AYYab &.$/ 90^{\circ}$ & $\mid \Psi / \backslash \Lambda^{\mathrm{d}-\mathrm{g}}$ & $\Lambda \circ / Y^{\mathrm{op}}$ & A & & \\
\hline$\vee / \Delta \Lambda^{\text {efg }}$ & $0 / 9400$ & $11 / 9 \mathrm{Vfg}$ & rV/AYq & B & 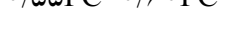 & \\
\hline$V / N \mu c b c d$ &.$/ 909^{\circ}$ & $Q / Q F_{\circ} g g$ & $101 / Y^{m n o}$ & A & 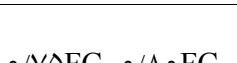 & \\
\hline$V /\left.\wedge \circ\right|^{b c}$ & $\circ / V \backslash \wedge^{n}$ & $1 Y / A r^{\mathrm{efg}}$ & $V \psi / 19 p$ & B & 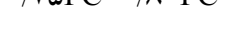 & مإسر \\
\hline$V / \varphi \circ Q \operatorname{def}$ & ०NG H Hn & N/DGYg & $৭ \hookrightarrow / 4 \Delta^{\text {nop }}$ & A & $0 \Delta 5 C \Gamma C$ & \\
\hline $\mathrm{V} / ৭ \hookrightarrow \Delta^{\mathrm{a}}$ & $\circ / \mathrm{Y} \wedge^{\mathrm{mn}}$ & $\mid r / \wedge q^{d-g}$ & $V Y^{\mathcal{C}} / \mathrm{V}^{\mathrm{p}}$ & B & $0 / 7 \omega \Gamma C-\Gamma C$ & \\
\hline$V / \Delta \varphi \Delta^{\mathrm{d}-\mathrm{g}}$ & ०NG & Tr/9qc-f & $|\Psi| / \Upsilon^{j k l}$ & A & $\triangle \triangle \triangle F C$ & \\
\hline$V / f y)^{\text {fgh }}$ & $\circ / \mathrm{V} \wedge)^{\mathrm{m}}$ & $\mathrm{IV} / \mathrm{O}^{\mathrm{c}-\mathrm{g}}$ & $9 \circ / T^{\text {nop }}$ & B & / & \\
\hline$V / \Delta r_{0}$ efg & -/VGqmn & $\mid \gamma / \Delta \xi^{d-g}$ & $\mid q v / V^{\mathrm{ij}}$ & A & $\circ \triangle \triangle F C$ & Ao \\
\hline$V / \& Y \varphi \Delta^{c d e}$ & $\circ / \Lambda 0^{1}$ & $r \circ / \Delta \wedge^{c-g}$ & $\| K / T^{\operatorname{lmn}}$ & B & 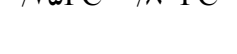 & wh \\
\hline$V / \mathcal{A} \circ \varphi^{g-j}$ & $\circ / 99 \mu^{k}$ & $r \circ / \Delta \wedge^{c-g}$ & $10 \mathrm{~V} / \mathrm{Y}^{\mathrm{hi}}$ & A & $\Delta \Delta \Gamma C, \Gamma C$ & \\
\hline V/G Y Vde & •/^৭০ & $\mid Q / \kappa^{c} V^{d-g}$ & $\mid r \mu / 4 k l m$ & B & $0 / 7 \omega \Gamma C-\Gamma C$ & \\
\hline$V / D / Y^{e-h}$ & $\circ / \wedge Q_{0} 1$ & $r Y / \circ \wedge^{c-f}$ & $\mid V V^{c} / \Delta^{h}$ & A & $\triangle \triangle \mathrm{EC} / \mathrm{E} \mathrm{EC}$ & \\
\hline$V / Y \nvdash \& j k l$ & ०/qVQj ${ }^{\mathrm{jk}}$ & $19 / \mu^{\mathrm{c}-\mathrm{g}}$ & $|\mathcal{F} /|^{\mathrm{ijk}}$ & B & 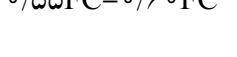 & \\
\hline$V / T G V^{\mathrm{i}-1}$ & ०/^৭૬l & $\mid V / G \psi^{c-g}$ & $r \circ \Delta / Y^{g}$ & A & $\circ \mathrm{VAFC} \circ \triangle \circ \mathrm{FC}$ & 10 \\
\hline$V / T \boldsymbol{Y}^{\mathrm{i}-1}$ & $1 / 0 \mid \wedge^{\mathrm{ij}}$ & $r Q / Y Y^{c d}$ & $190 / 0^{\mathrm{hi}}$ & B & 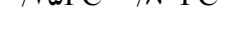 & 10 \\
\hline$V / T \Delta \zeta^{\mathrm{i}-1}$ & $1 / \circ{ }^{\varphi} \wedge^{\mathrm{i}}$ & $1 \mu / \mu^{\mathrm{d}-\mathrm{g}}$ & $r \circ \Delta / V^{g}$ & A & $. / 9 \Delta \mathrm{FC}-\mathrm{FC}$ & \\
\hline V/Fץ^ghi & $1 / 1 \circ 9 h$ & $r_{0} / \psi^{c} \varphi^{c-g}$ & $190 / Y^{\mathrm{hi}}$ & B & & \\
\hline$V / \mu Y \Delta^{h-k}$ & $1 / 19 \circ g h$ & $r \Delta / \Psi^{\leftarrow} \wedge^{\mathrm{cd}}$ & TVT/qe & A & $\circ \triangle A \mathrm{FC}-\circ / \varepsilon \circ \mathrm{FC}$ & \\
\hline$V /\left.Y^{\prime}\right|^{\mathrm{kl}}$ & $1 / \pi 9 \wedge^{\mathrm{h}}$ & $10 / V^{\mathrm{d}-\mathrm{g}}$ & $r \mu \Delta / q^{f}$ & B & / & \\
\hline $\mathrm{V} / \circ \circ 9^{\mathrm{m}}$ & $1 / 194 \mathrm{~g}$ & $r Y / r \mu^{c}-f$ & $r 90 / \mathrm{d}^{\mathrm{d}}$ & A & $\circ \mathrm{V} \triangle \mathrm{FC}$ & Y \\
\hline $9 / 999 \mathrm{~m}$ & $1 / T a \varphi^{f}$ & $Y Q / \circ V^{c d e}$ & $r \times T / D^{f}$ & B & 年 & \\
\hline$V / Y I Y^{\mathrm{kl}}$ & $1 / \Gamma \wedge V^{e}$ & $\mid \xi / \mu^{\mathrm{d}-g}$ & $\mu / T / V^{c d}$ & A & ०/90FC-FC & \\
\hline $\mathrm{V} / \mathrm{l} \circ \mathrm{rlm}$ & $1 / 4 T \Delta^{e}$ & $|V / 0|^{c-g}$ & $Y Y^{\mathbb{L} V / I^{f}}$ & B & & \\
\hline V/Trqjkl & $1 / 990^{\circ}$ & $\mid r \Delta / \Delta^{\mathrm{a}}$ & $r Y I / T^{c}$ & A & C & \\
\hline$V / 190^{\mathrm{kl}}$ & $1 / \Delta \mu_{0} d$ & $V a / r q b$ & $r q / / l^{c d}$ & B & 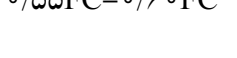 & \\
\hline $9 / 94 \circ \mathrm{mn}$ & $1 / 999^{c}$ & $19 / 00^{c-g}$ & $\forall \vee / q^{a}$ & A & $\triangle \triangle A C$ & 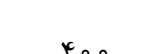 \\
\hline $9 / 1 V 990$ & $1 / A V^{\mu b}$ & $r \Lambda / T q^{c}$ & $p r \circ / q^{b}$ & B & fre tre & \\
\hline$V / \circ Y^{\prime m}$ & $1 / 9 \mu_{\circ} a$ & $\mid Q / \backslash \wedge^{\mathrm{d}-\mathrm{g}}$ & $4 q \circ / \mu^{a}$ & A & $\mathrm{EC} \mathrm{EC}+2$ & \\
\hline $4 / \Lambda \mid Q^{\text {no }}$ & $1 / 94 \wedge^{\mathrm{a}}$ & $\mid Q / \wedge V^{d-g}$ & $k T \circ / T^{\mathrm{b}}$ & B & 列 & \\
\hline
\end{tabular}


قابل ملاحظهاى مهار مى شود (V) (شكل \&). اثر متقابـل غلظـت

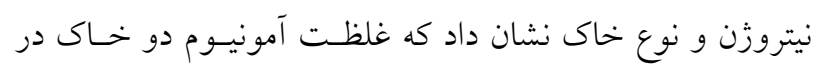

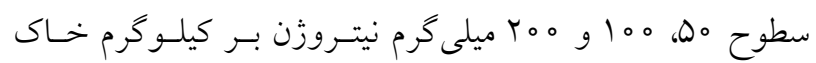

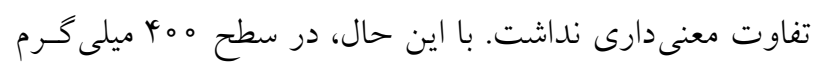

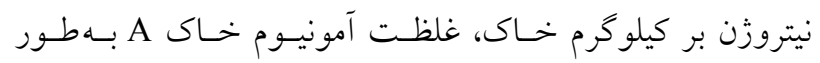

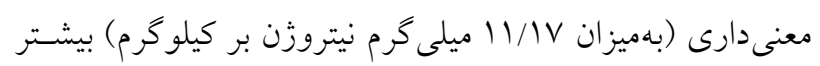

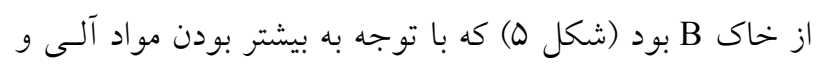

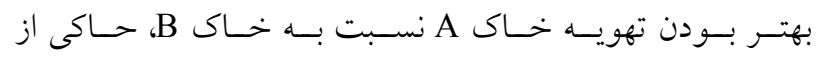

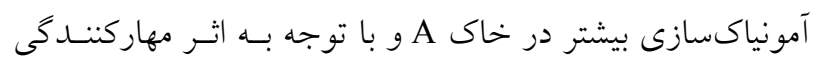

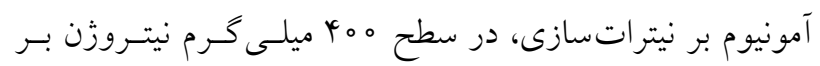

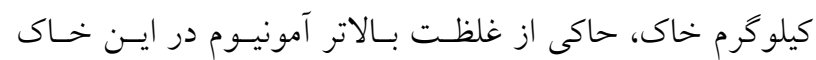

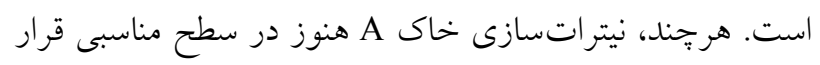

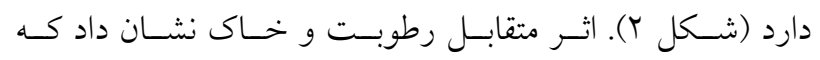

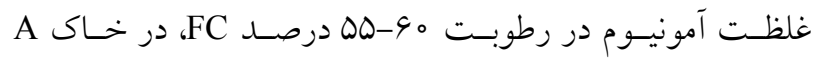

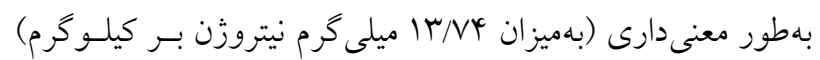

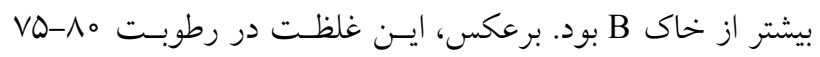

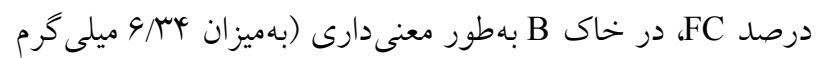

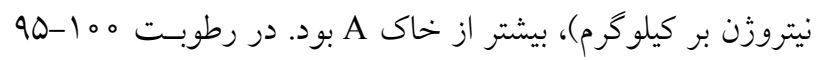

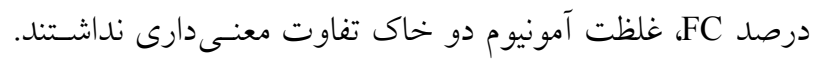

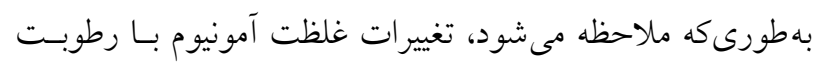

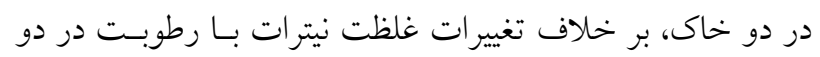

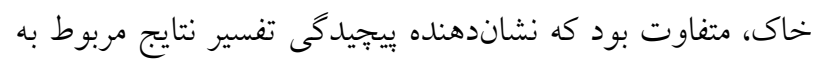

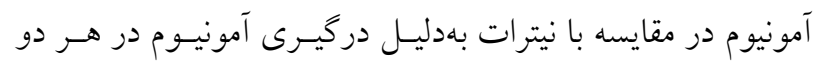

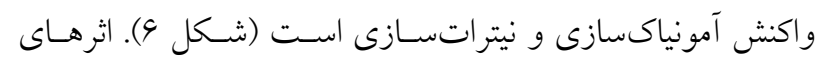

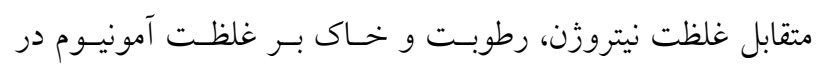

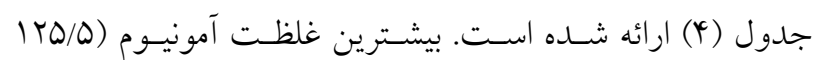

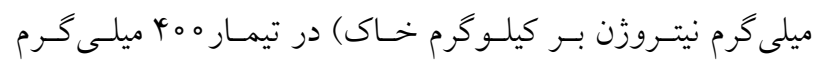

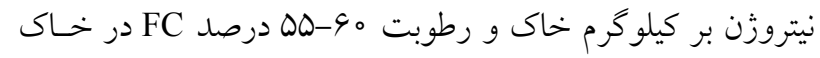

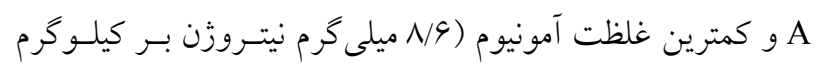

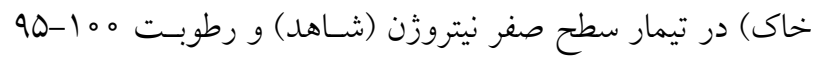

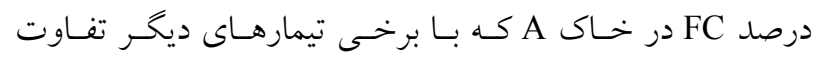
معنى مارى نداشت، مشاهده شد.

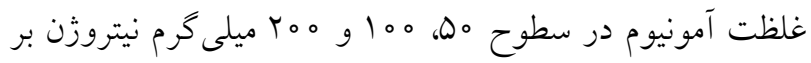

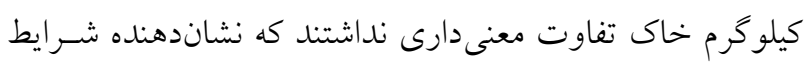

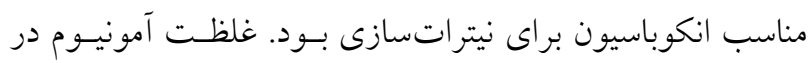

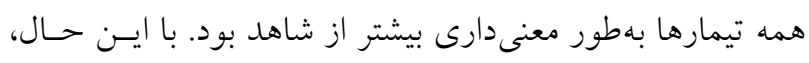

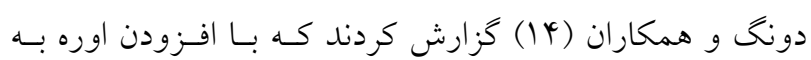

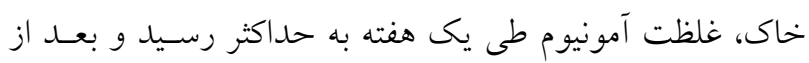

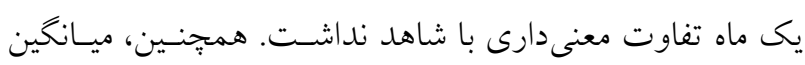

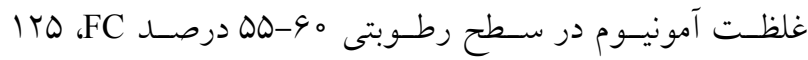

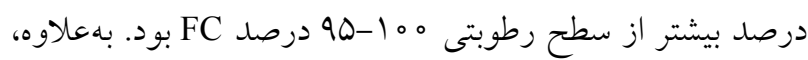

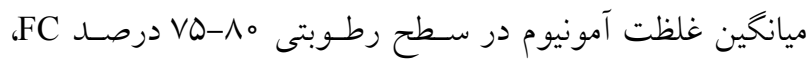
TY/

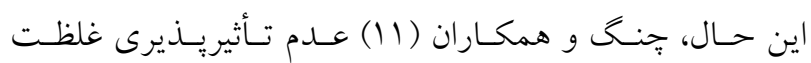

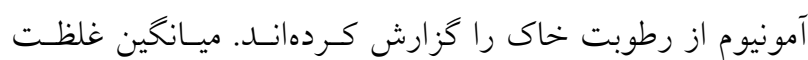

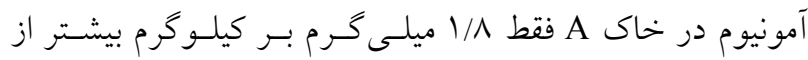
خاى B مبود. اثر متقابل غلظت نيتروزن و رطوبت نشان داد كه با افزايش

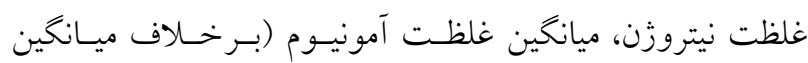

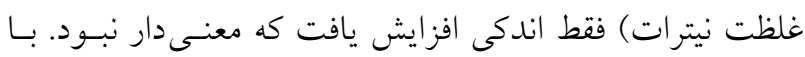

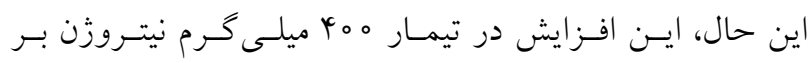

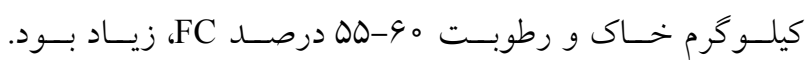

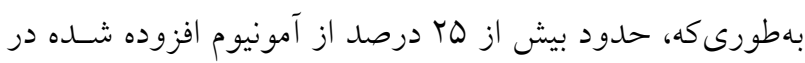

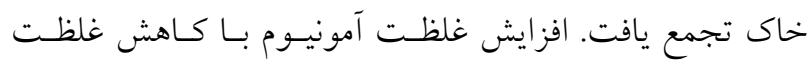

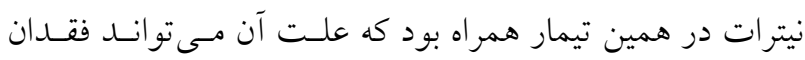
رطوبت كافى براى بخشيدكى آمونيوم به سمت باكترى در خاك

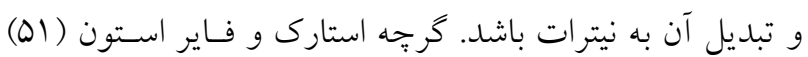
محسـوديت فراهمسى سوبسـترا را در رطوبـــهــاى بــالاتر نيـز

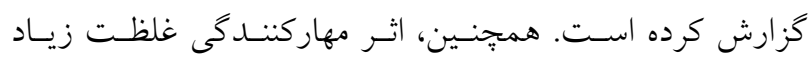

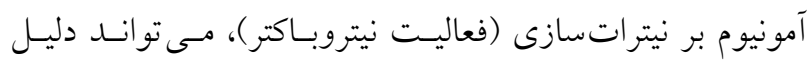

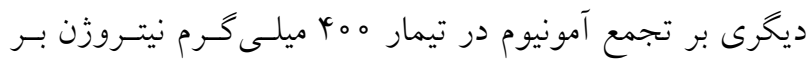

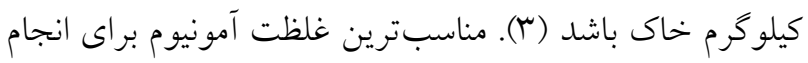

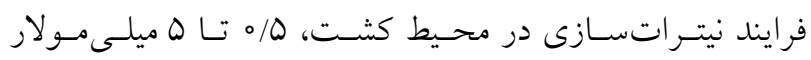

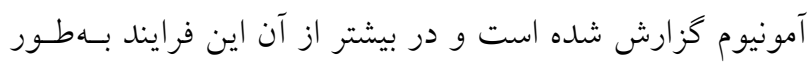




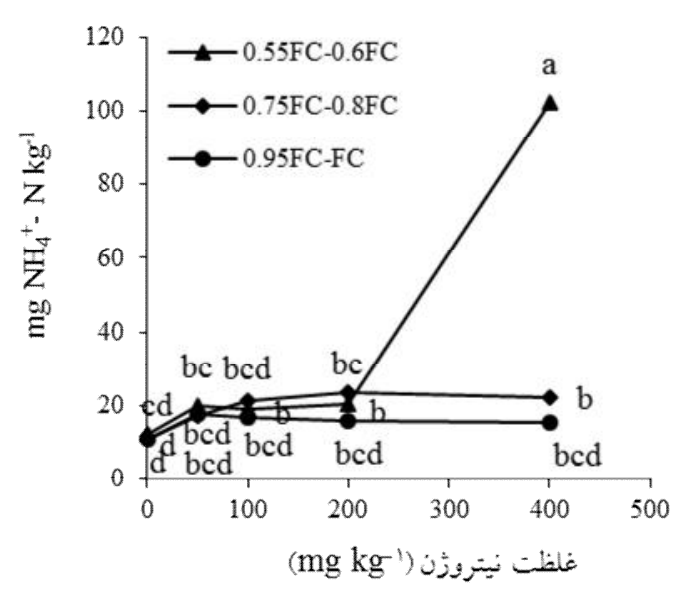

شكل هـ اثر متقابل غلظت نيتروزن و نوع خاك بر غلظت آمونيوم

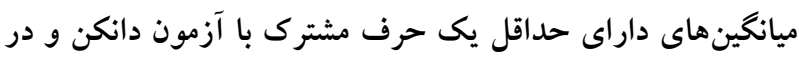
سطح احتمال بنج درصد تفاوت معنادارى ندارند.

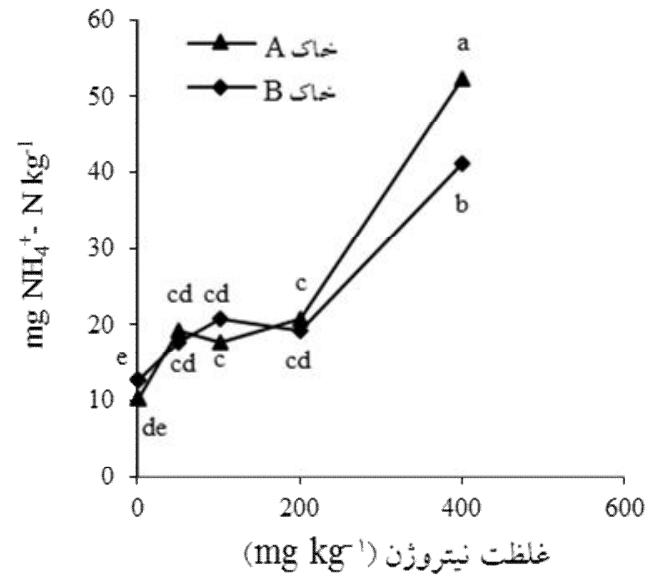

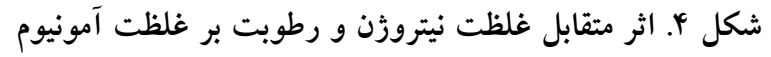

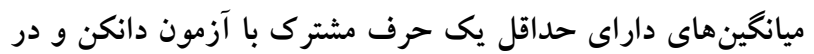
سطح احتمال ينج درصد تفاوت معنادارى ندارند.

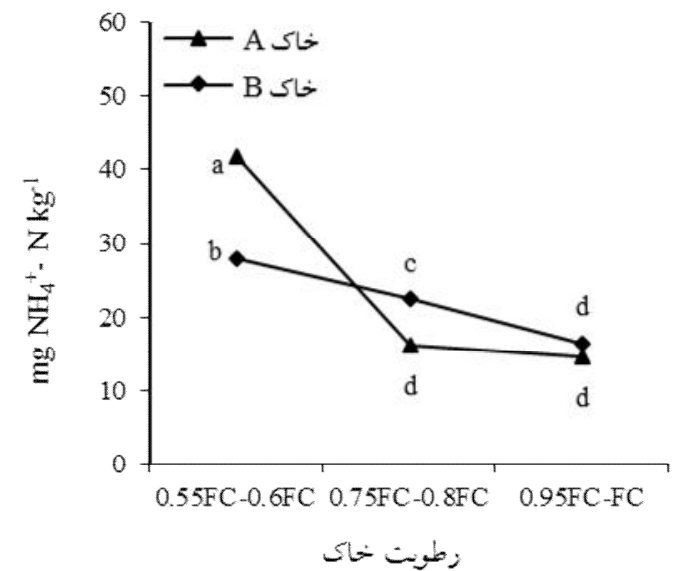

شكل 9 .اثر متقابل رطوبت و نوع خاك بر غلظت آمونيوم. ميانكينهاى داراى حداقل يك حرف مشترك با

آزمون دانكن و در سطح احتمال بنج درصد تفاوت معنادارى ندارند.

متعاقباً به يونهاى نيترات و يروتون تبديل مىشود، بهطور مستقيم

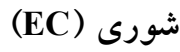

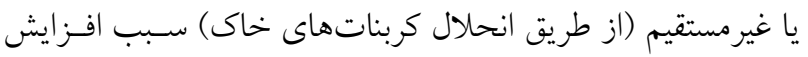
تجزيه واريانس دادهها (جدول r) نشـان داد كـه اثـرات اصـلى غلظت نمكهاى محلول و در نتيجه افزايش EC مىشود. مالهى و غلظت نيتروزن، رطوبـت و خــاك و اثرهـاى متقابـل غلظـت و

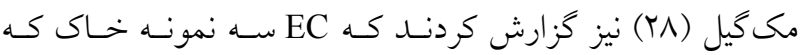

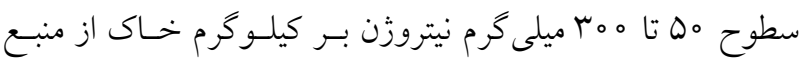
رطوبت، غلظت و خاك، رطوبت و خاك، و غلظت و رطوبت و خاك در سطح احتمال يك درصد معنىدار شدند. سولفات آمونيوم را در رطوبت FC دريافت كرده بودنـد، بسين

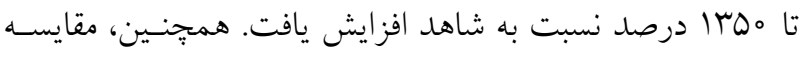

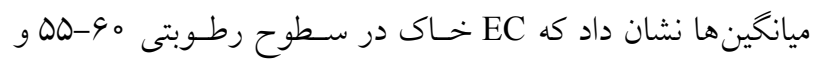

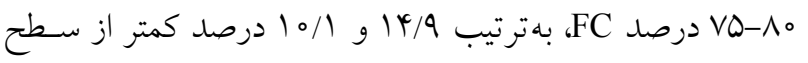

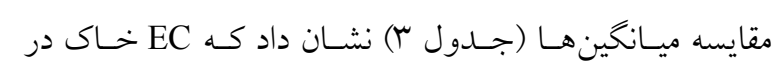

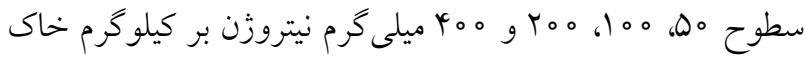

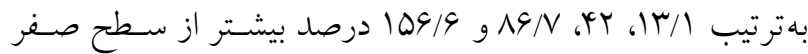

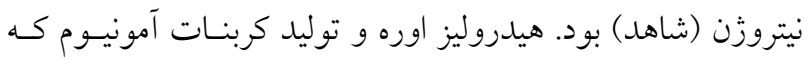




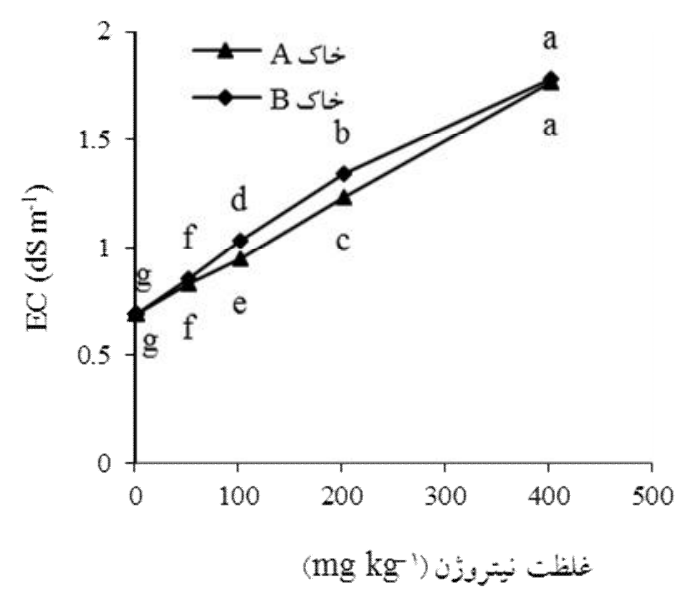

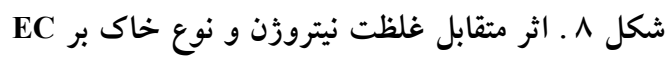

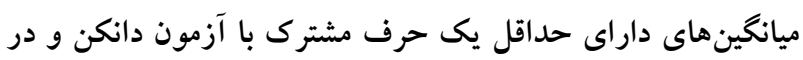
سطح احتمال ينج درصد تفاوت معنادارى ندارند.

خاك بر EC خاك در جدول (Y) ارائه شده است. بيشـترين

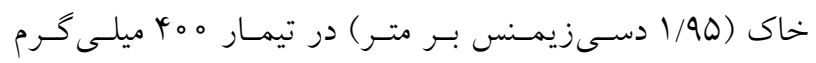

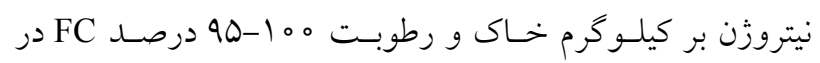

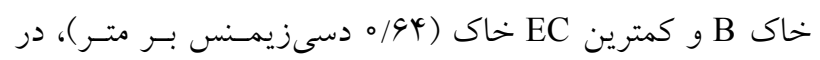

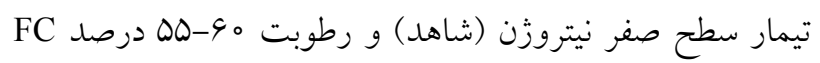

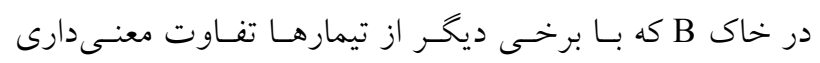
نلداشت، مشاهده شلد.

pH

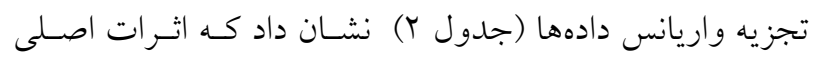
غلظت نيتروزن و رطوبت بر pH در سطح احتمال يـى درصـــ

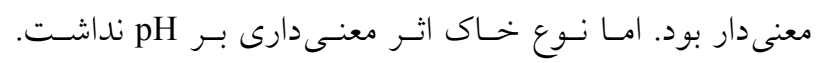
همجنين، اثرهاى متقابل غلظت و رطوبت، غلظت و نوع خـاك،

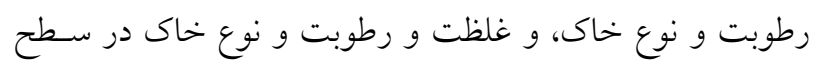
احتمال يك درصد معنى دار شدند.

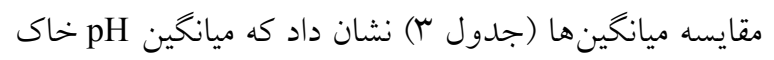

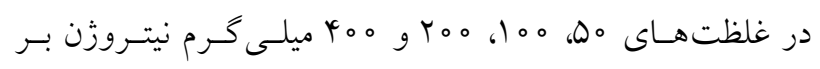

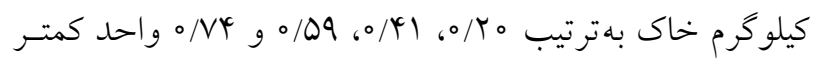

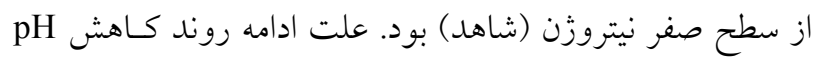

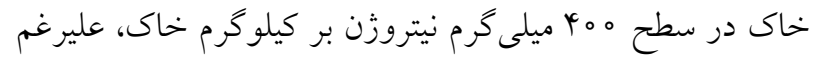

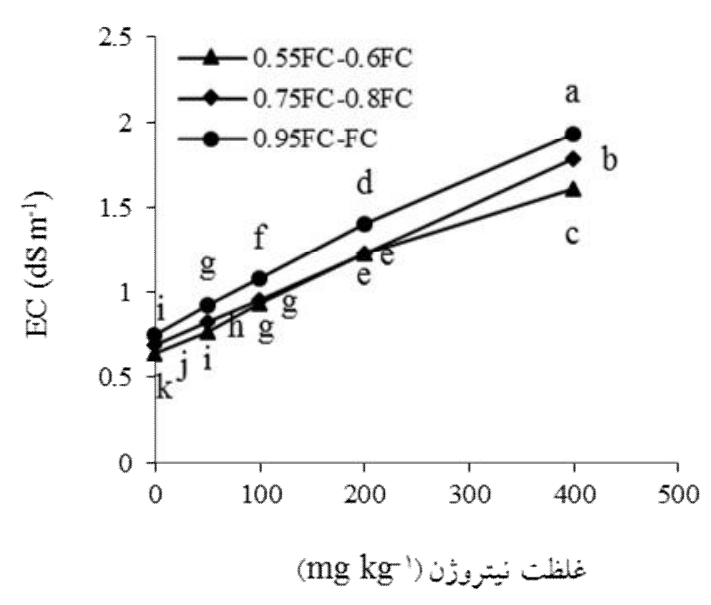

شكل V. اثر متقابل غلظت نيتروزن و رطوبت بر EC ميانكين هاى داراى حداقل يكى حرف مشترى با آزمون دانكن و در سطح احتمال ينج درصد تفاوت معنادارى ندارند.

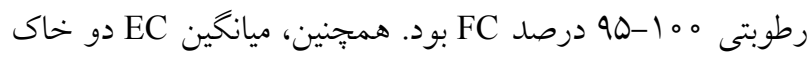

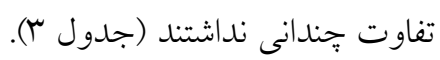

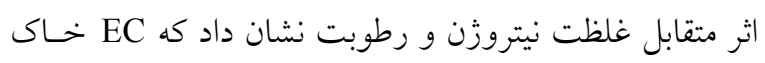

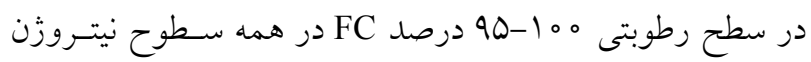
بيشتر از دو سطح رطوبتى ديخر بود (شكل V). فراهمى رطوبت،

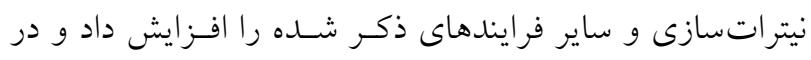

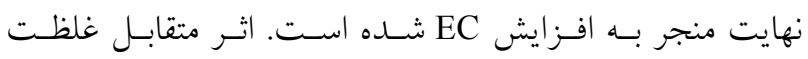

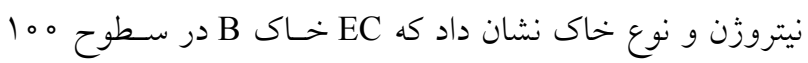

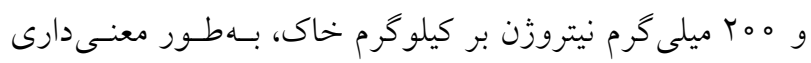

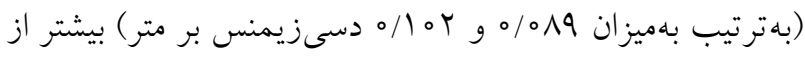

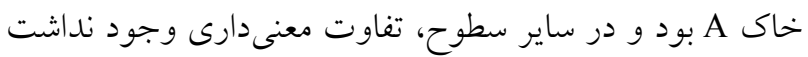

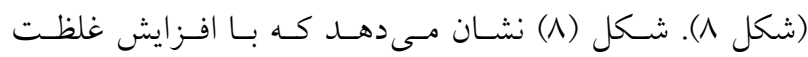
نيتروزن، EC خاى تقريباً به شكل خطى افزايش يافت. با توجسه

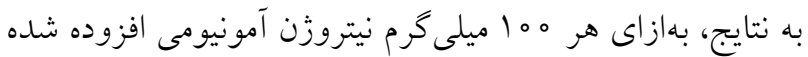

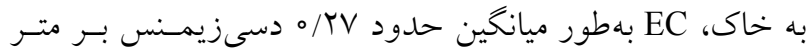

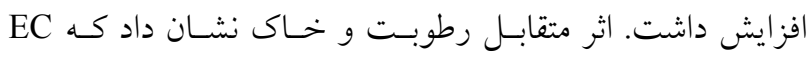

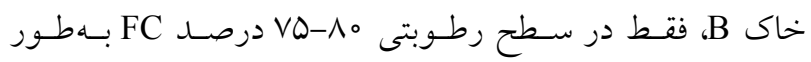

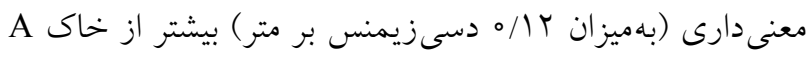

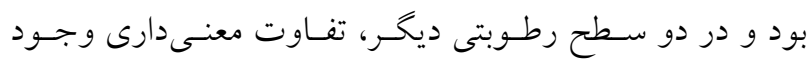

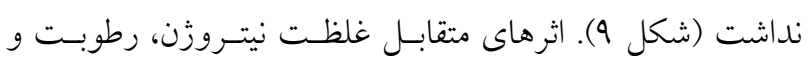




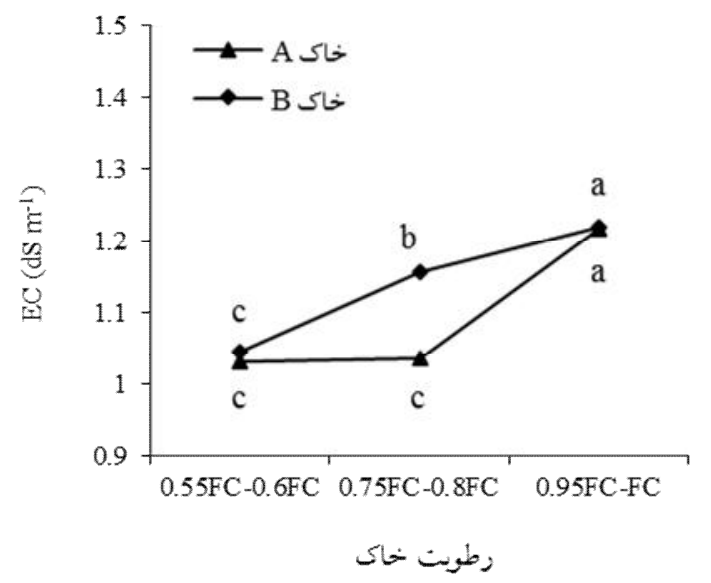

شكل 9. اثر متقابل رطوبت و نوع خاك بر EC. ميانگينهاى داراى حداقل يك حرف مشترك با آزمون دانكن و در سطح احتمال بنج درصد تفاوت معنادارى ندارند.

واحد كمتر از سطح رطوبتى ه 0 ا-90 درصسد FC بـود. ميـانكين

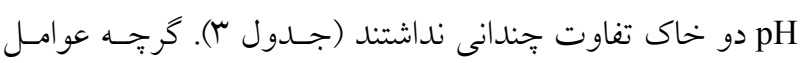

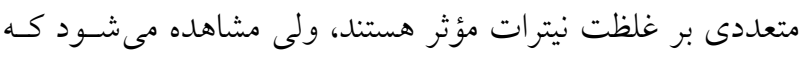

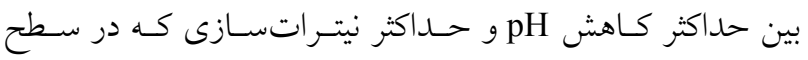

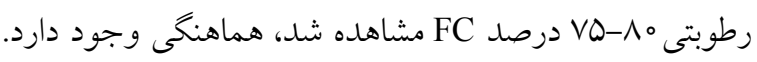

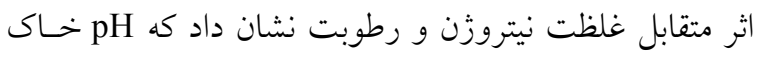

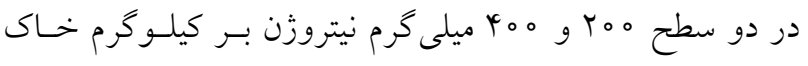

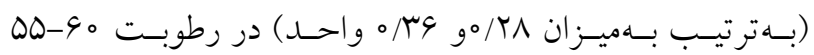

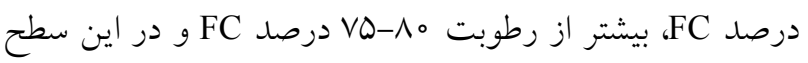

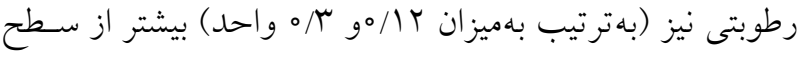

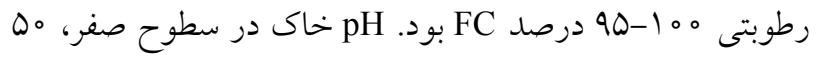
و ه ما ميلى گرم نيتروزن بر كيلو گرم خـاك تفـاوت معنسى دارى نداشتند (شكل • (). بهطوركلى، تأمين رطوبت و نيتـراتسـازى

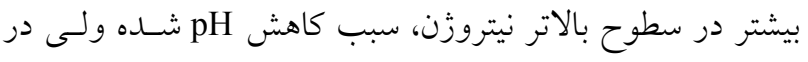

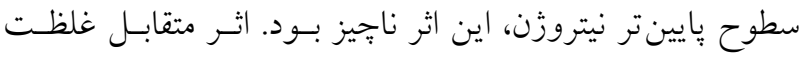

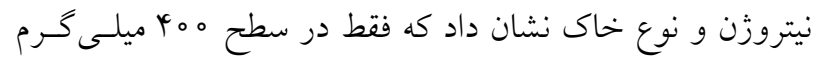

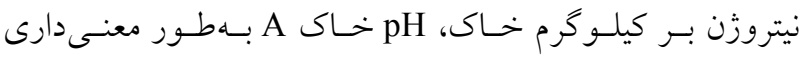

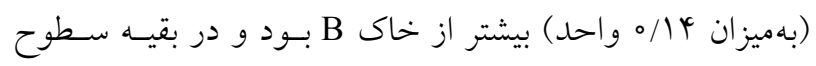

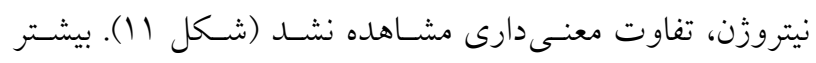
بودن pH خاك A نسبت به خاك B در بالاترين سطح نيتـروزن را مى توان به آمونياكسـازى بيشـتر در خـاك A د در مقايسـه بـا
كاهش نيتراتسـازى، مسى توانـــ اسـتمرار رهاسـازى بروتــون در

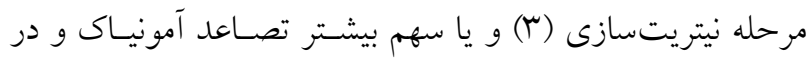

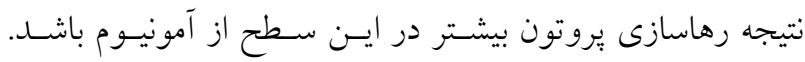

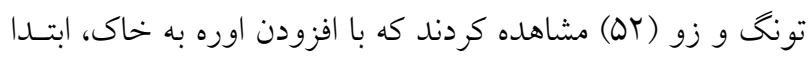

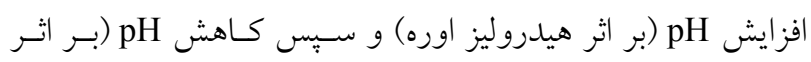

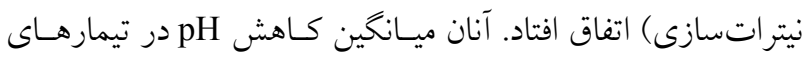

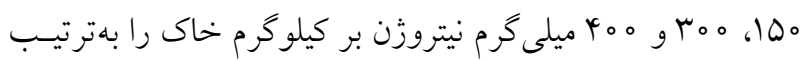

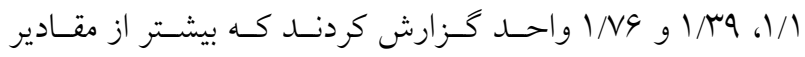

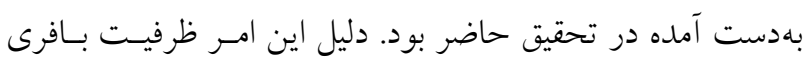
كمتر اين خاكها در مقايسه با تحقيق حاضر بـود. ميـانخين CEC

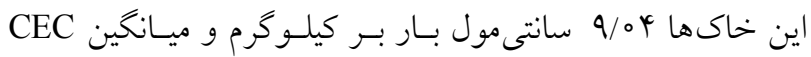
خاكها در تحقيق حاضر، T/D/D سانتى مول بار بـر كيلسوخرم بـود. مطالعات دونخ و همكاران (Y) نيز نشان داد كه pH بـا افـزودن

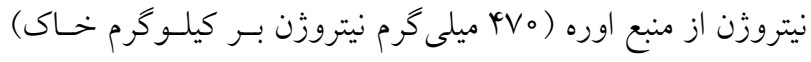

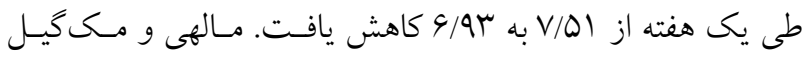

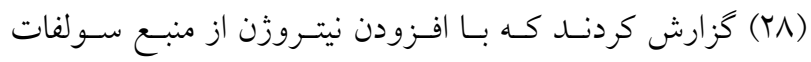

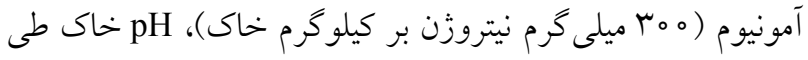

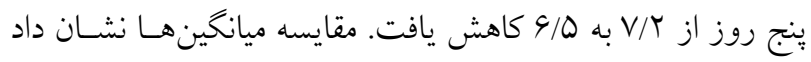

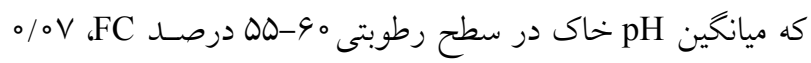

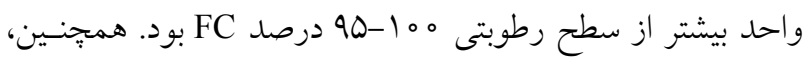

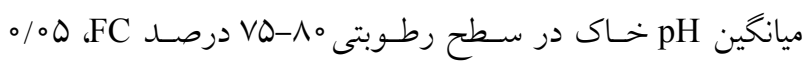




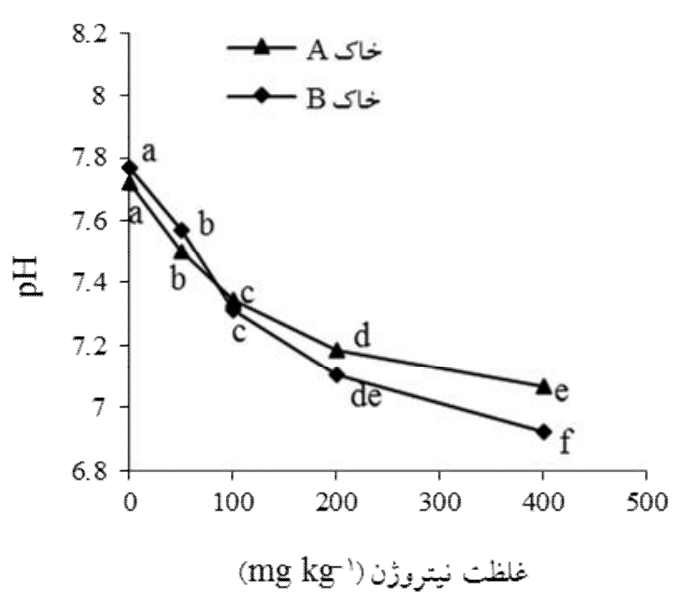

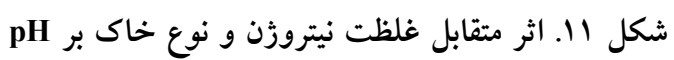

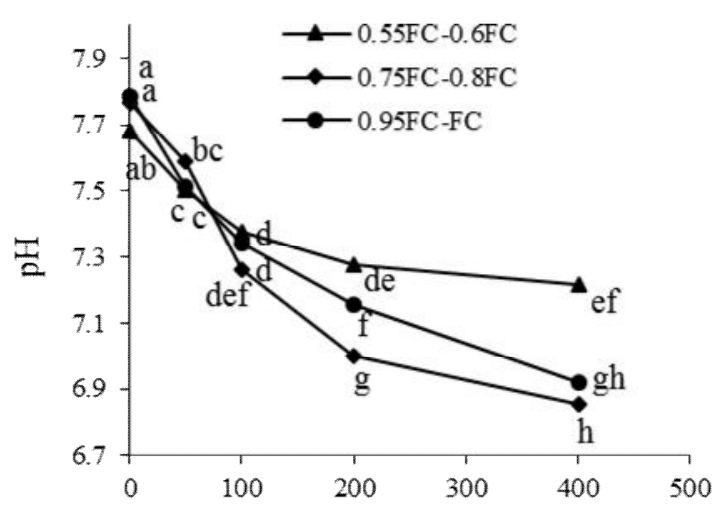

غلظت نيتروزن (mg kg-')

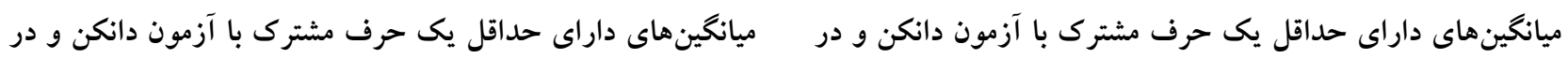
سطح احتمال ينج درصد تفاوت معنادارى ندارند. سطح احتمال ينج درصد تفاوت معنادارى ندارند.

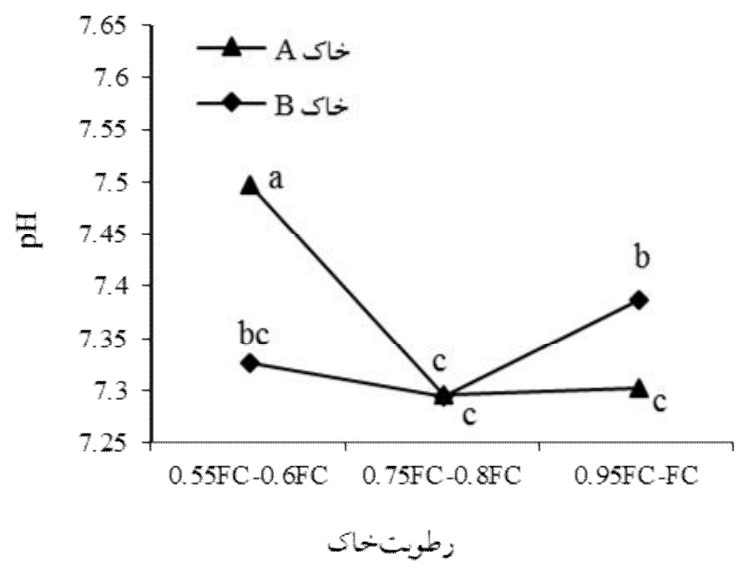

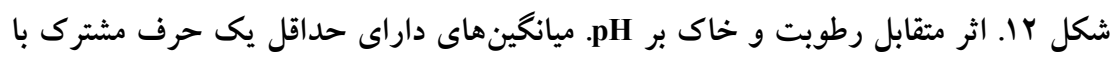
آزمون دانكن و در سطح احتمال ينج درصد تفاوت معنادارى ندارند.

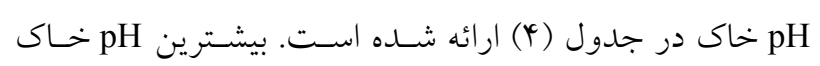

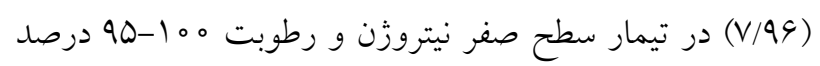

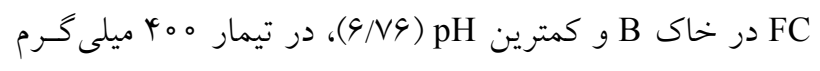

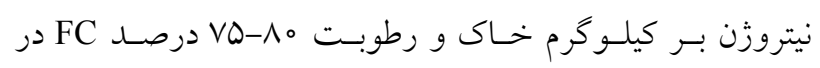

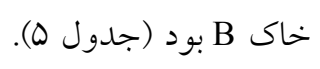

\section{نرخ نيتراتسازى}

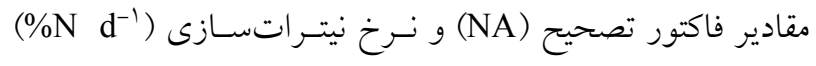
بعد از دو هفته انكوباسيون در جــدول (ه) ارائسه شـــه اسـت.

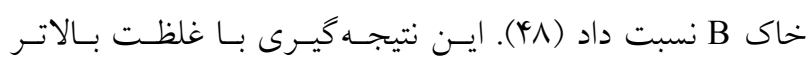

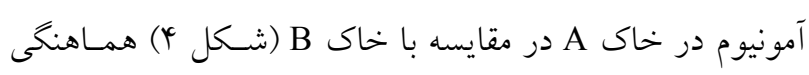

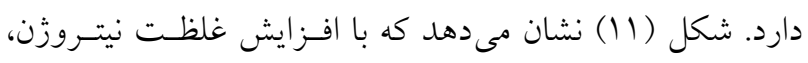

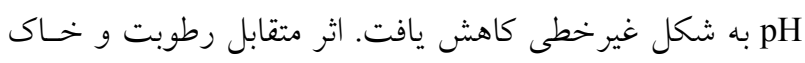

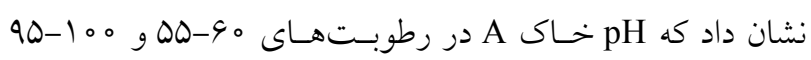

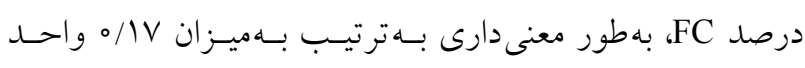

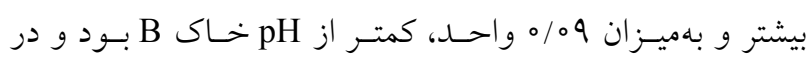

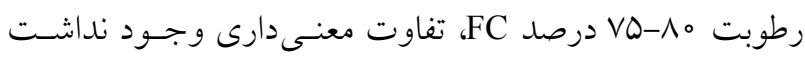
(شكل r I ). اثرهاى متقابل غلظت نيتروزن، رطوبت و خـاك بـر 
جدول ه. مقادير فاكتور تصحيح (NA) و نرخ نيتراتسازى (1\% d ه $\left.^{-1}\right)$ بعد از دو هفته انكوباسيون در سطوح مختلف

نيتروزن و رطوبت در دو خاى A و

\begin{tabular}{|c|c|c|c|c|}
\hline$\% \mathrm{~N} \mathrm{~d}^{-1}$ & $\begin{array}{c}\mathrm{NA} \\
\left(\mathrm{mg} \mathrm{N} \mathrm{kg}^{-1} \text { soil }\right)\end{array}$ & $\begin{array}{c}\text { سطح نيتروزن } \\
\text { (mg urea-N kg-1 soil) }\end{array}$ & رطوبت & نوع خاك \\
\hline $9 / 0 \mu$ & $10 / \mathrm{V}$ & め。 & \multirow{4}{*}{$\circ / \Delta \Delta \mathrm{FC}-\circ / 9 \circ \mathrm{FC}$} & \multirow{12}{*}{ A } \\
\hline 9/0 & $r / 19$ & 100 & & \\
\hline s/VI & $4 / 99$ & roo & & \\
\hline$Y / \wedge V$ & $-4 \varphi / \Lambda$ & Yoo & & \\
\hline $9 / 0 \mathrm{r}$ & $N / Q V$ & Q. & \multirow{4}{*}{$\circ / \mathrm{V} Q \mathrm{FC}-\circ / \wedge \circ \mathrm{FC}$} & \\
\hline $9 / 94$ & $M / r$ & 100 & & \\
\hline s/V。 & $4 / 94$ & Y०० & & \\
\hline$V / 01$ & $-Y Y / T$ & yoo & & \\
\hline $0 / 99$ & $r$ r/Vq & Q. & \multirow{4}{*}{$\circ / 9 \Delta \mathrm{FC}-\mathrm{FC}$} & \\
\hline G/Ar & $14 / 40$ & 100 & & \\
\hline $9 / 90$ & 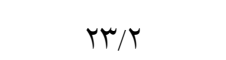 & Y०० & & \\
\hline$V / \circ T^{2}$ & $\circ / 0 \circ V$ & yoo & & \\
\hline $9 / 4 \wedge$ & $V / V Q$ & ఎ० & \multirow{4}{*}{$\circ / \Delta \Delta \mathrm{FC}-\circ / 9 \cdot \mathrm{FC}$} & \multirow{12}{*}{ B } \\
\hline G/A & N/9T & 100 & & \\
\hline $\mathrm{V} / \mathrm{\circ} \circ$ & I/VA & Y०。 & & \\
\hline $0 / 9 \mathrm{~V}$ & $-V Y / 1$ & Yoo & & \\
\hline $9 / 10$ & $r / 04$ & Q. & \multirow{4}{*}{$\circ / \mathrm{V} \Delta \mathrm{FC}-\circ / \wedge \circ \mathrm{FC}$} & \\
\hline $9 / 49$ & $r / N$ & 100 & & \\
\hline $9 / V 0$ & $-V / \Lambda$ & roo & & \\
\hline G/A & $-Y T / 9$ & Yoo & & \\
\hline $9 / 94$ & $\circ / \Lambda \wedge r$ & ఎ. & \multirow{4}{*}{$\circ / 9 \Delta \mathrm{FC}-\mathrm{FC}$} & \\
\hline $9 / 99$ & $-Y / 9 V$ & 100 & & \\
\hline$V / \circ Y$ & $-Y Y / 9$ & roo & & \\
\hline$V / 1 \circ$ & $-Q Y / \Delta$ & roo & & \\
\hline
\end{tabular}

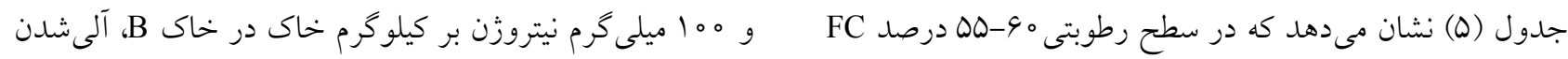

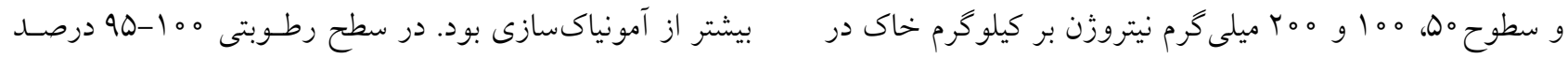

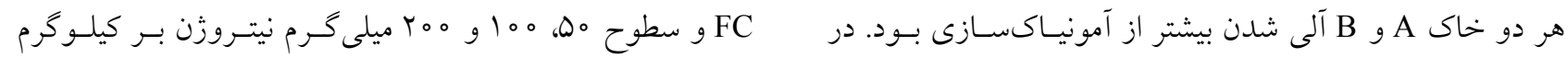

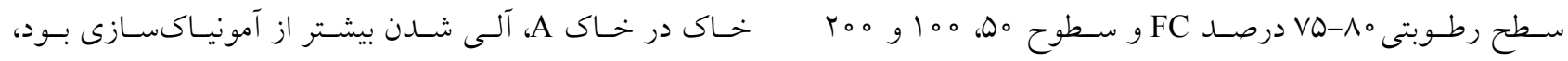

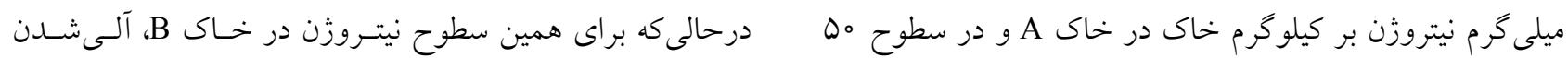


$9 / 10 \% \mathrm{~N} \mathrm{~d}^{-1}$ و 9/91\% \% d بهدست آملا.

$$
\text { نتيجه كيرى }
$$

نتايج نشان داد كه كاهش رطوبـت خـاك تـا VQ درصــ FC در هيجيك از سطوح نيتروزن، تأثير معنسى دارى بـر نيتـراتسـازى نداشت. كاهش رطوبت تا هه درصـد FC، نيتـراتسـازى را در همه سطوح نيتروزن بهطور معنى دار كـاهش داد، ولـى بيشـترين كاهش در بالاترين سطح آمونيوم مشاهده شد. اين ميزان كاهش

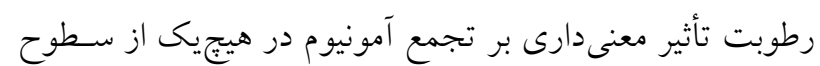
نيتروزن بهاستثناى بالاترين سطح نداشـت. EC خـاى در سـطح رطوبتى ه ه -ه 9 درصد FC، در همه سطوح نيتسروزن بـهـور معنى دارى بيشتر از دو سطح رطوبتى ديخر بود. در سطوح يايين نيتروزن، اثر رطوبت بر خH خاك نـاجيز بـود، ولـى در سطوح بالاتر، با كاهش رطوبت، pH افزايش يافت.
كمتر از آمونياكسازى بود. همجِنين، براى همه سطوح رطوبـت

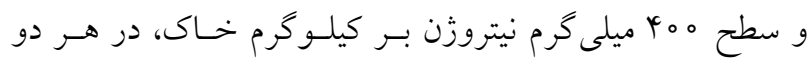
خاى A و B، آلى شدن كمتر از آمونياكسازى بود. بهطـوركلى، نتايج نشان مي دهد در كليه تيمارهـايى كـه آلى شـــ كمتـــ از آمونياكسازى بود، غلظت نسـبى نيتـرات در بايـان انكوباسـيون

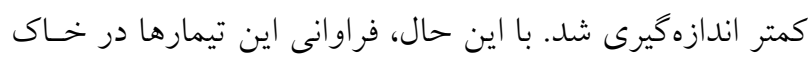
B بيشتر از خاك A بود كه علت آن را مسىتـوان بـه اسـتخراج مقادير كمتر آمونيوم از اين خاك بهدليل بافـت ريزتـر و تثبـتـت

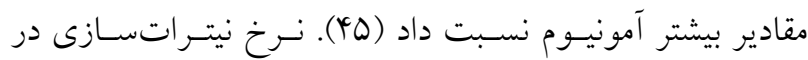

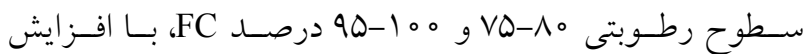
غلظت نيتروزن افـزيش يافـت. بـرعكس، ايسن نـرخ در سـطح رطوبتى 09-هاه درصــ FC FC، ابتـدا بـا افـزايش غلظـت نيتـروزن

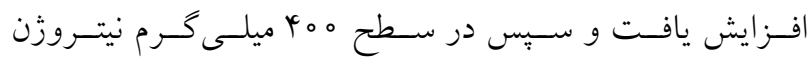

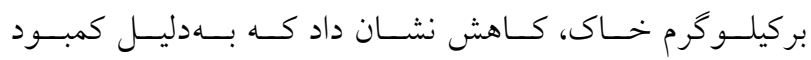

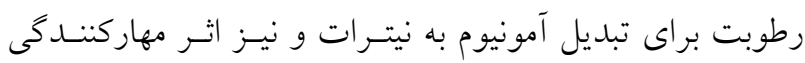

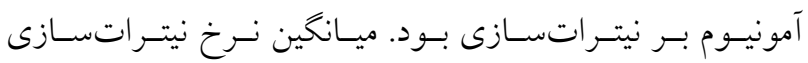

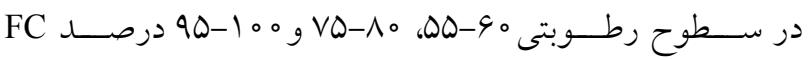

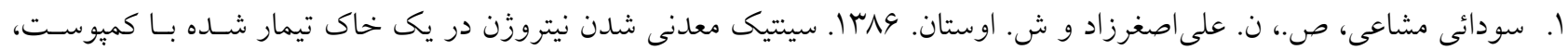

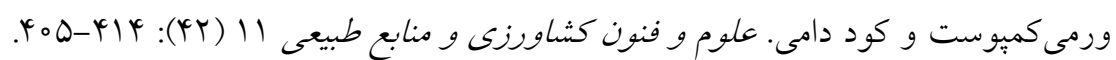

ז. على اصغرزاد، ن.هیrا. روش هاى آزمايشخاهى در بيولوثى خاك (ترجمه). انتشارات دانشخاه تبريز. تبريز.

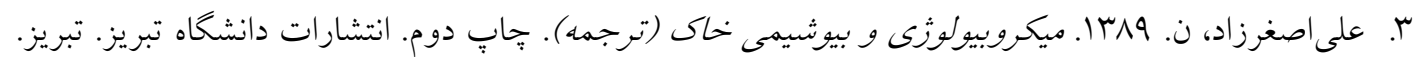

4. Alexander, M. 1977. Introduction to Soil Microbiology. $2^{\text {nd }}$ Edition. John Wiley \& Sons, New York.

5. Allison, L. E. and C. D. Moodie. 1965. Carbonate. PP. 1379-1396. In: C. A. Black et al. (Eds.) Methods of Soil Analysis, Part 2. Chemical and Microbiological Properties. American Society of Agronomy, Madison, WI.

6. Black, A. S. and S. A Waring. 1978. Nitrate determination in an Oxisol using $\mathrm{K}_{2} \mathrm{SO}_{4}$ extraction and the nitratespecific ion electrode. Plant and Soil 49: 207-211.

7. Bloem, J., D. W. Hopkins and A. Benedetti. 2006. Microbiological Methods for Assessing Soil Quality. CABI Publishing, Wallingford, Oxfordshire OX10 8DE, UK.

8. Carlyle J. C., J. R. Lowther, P. J. Smethurst and E. K. S. Nambiar.1990. Influence of chemical properties on nitrogen mineralization and nitrification in podzolized sands. Implications for forest management. Australian Journal of Soil Research 28: 981-1000.

9. Chapman, H. D. 1965. Cation exchange capacity. PP. 891-901. In: C. A. Black et al. (Eds.). Methods of Soil Analysis. Part 2. Chemical and Microbiological Properties. American Society of Agronomy, Madison, WI.

10. Chen, Y. T., W. Borken, C. F. Stange and E. Matzner. 2011. Effects of decreasing water potential on gross ammonification and nitrification in an acid coniferous forest soil. Soil Biology and Biochemistry 43: 333-338.

11. Cheng, Y., Z. C. Cai, J. B. Zhang, M. Lang, B. Mary and X. C. Scott. 2012. Soil moisture effects on gross nitrification differ between adjacent grassland and forested soils in central Alberta, Canada. Plant and Soil 352: 
$289-301$.

12. Cheng, Y., J. Wang, S. Q. Wang, J. B. Zhang and Z. C. Cai. 2014. Effects of soil moisture on gross N transformations and $\mathrm{N}_{2} \mathrm{O}$ emission in acid subtropical forest soils. Biology Fertilizer Soils 50: 1099-1108.

13. Clough T. J., G. J. Lanigan, C. A. M. de Klein, M. S. Samad, S. E. Morales, D. Rex, R. L. Bakken, C. Johns, L. M. Condron, J. Grant and K. G. Richards. 2017. Influence of soil moisture on codenitrification fluxes from a ureaaffected pasture soil. Scientific Reports 7(1): 21-85.

14. Dong, L., A. L. Cordova-Kreylos, J. Yang, H. Yuan and K. M. Scow. 2009. Humic acids buffer the effects of urea on soil ammonia oxidizers and potential nitrification. Soil Biology and Biochemistry 41: 1612-1621.

15. Dubey, H. D. 1968. Effect of soil moisture levels on nitrification. Canadian Journal of Microbiology 14: 13481350.

16. Flowers, T. H. and J. R. O'Callaghan. 1983. Nitrification in soils incubated with pig slurry or ammonium sulphate. Soil Biology and Biochemistry 15(3): 337-342.

17.Gavlak, R. G., D. A. Horneck, R. O. Miller and J. Kotuby-Amacher. 2003. Soil, Plant and Water Reference Methods for the Western Region. $2^{\text {nd }}$ Edition. WCC-103 Publication, WREP-125. University of Alaska, Fairbanks.

18. Gee, G. W. and J. W. Bauder. 1986. Particle-size analysis. PP. 383-411. In: A. Klute (Ed.). Methods of Soil Analysis. Part 2. American Society of Agronomy, Madison, WI.

19. Gödde, M. and R. Conrad .2000.Influence of soil properties on the turnover of nitric oxide and nitrous oxide by nitrification and denitrification at constant temperature and moisture. Biology and Fertility of Soils 32: 120-128.

20. Hayatsu, M. and N. Kosuge 1993. Autotrophic nitrification in acid tea soils. Soil Science and Plant Nutrition 39: 209-217.

21. Haynes, R. J. 1986. Nitrification, PP. 127-165. In: R. J. Haynes (Ed.), Mineral Nitrogen in the Plant-Soil System. Academic Press, New York.

22. Hulpoi, N., S. Dakesian, GH. Eliade and L. Ghinea.1970.The effect of soil physical conditions on the nitrification of $\mathrm{NH}_{4}$. Plant and Soil 32: 468-477.

23. Jiang, X., X. Shi, W. Liu and L.W. Alan. 2011. Kinetics of net nitrification associated with soil aggregates under conventional and no-tillage in a subtropical rice soil. Plant and Soil 347: 305-312.

24. Kirkham, M. B. 2014. Principles of Soil and Plant Water Relations. $2^{\text {nd }}$ Edition. Academic Press. Elsevier, Amsterdam.

25. Kladivko E. J. and D. R. Keeney.1987. Soil nitrogen mineralization as affected by water and temperature interactions. Biology and Fertility of Soils 5: 248-252.

26. Krave, A. S., N. M. Van Straalen and H. W. Van Verseveld. 2002. Potential nitrification and factors influencing nitrification in pine forest and agricultural soils in Central Java, Indonesia. Pedobiologia 46: 573-594.

27. Mahmoud, S. A. Z., Y. Z. Ishac, S. H. Salem and M. Z. El-Fouly. 1980. Effect of urea application at different rates on the microbial activity and mineralization of urea in Egyptian soils. Zentralblatt für Bakteriologie, Parasitenkunde, Infektionskrankheiten und Hygiene. Zweite naturwissenschaftliche Abteilung: Mikrobiologie der Landwirtschaft der Technologie und des Umweltschutzes. 135(6): 501-509.

28. Malhi, S. S. and W. B. McGill. 1982. Nitrification in three Alberta soils: Effect of temperature, moisture and substrate concentration. Original Research Article. Soil Biology and Biochemistry 14(4): 393-399.

29. Martikainen, P.1985.Nitrification in forest soil of different $\mathrm{pH}$ as affected by urea, ammonium sulphate and potassium sulphate. Soil Biology and Biochemistry 17(3): 363-367.

30. Nelson, D. W. and L. E. Sommers. 1982. Total carbon, organic carbon, and organic matter. PP. 539-579. In: A. L. Page et al. (Eds.), Methods of Soil Analysis, Part 2. Chemical and Microbiological Properties. American Society of Agronomy, Madison, WI.

31. Nishio, T. and T. Fujimoto. 1990. Kinetics of nitrification of various amounts of ammonium added to soils. Soil Biology and Biochemistry 22(1): 51-55.

32. Nishio, T., T. Kanamorj and T. Fujimoto. 1985. Nitrogen transformations in an aerobic soil as determined by a ${ }^{15} \mathrm{NH}_{4}{ }^{+}$dilution technique. Soil Biology and Biochemistry 17(2): 149-154.

33. Norton, J. M. and J. M. Stark. 2011. Regulation and measurement of nitrification in terrestrial systems. PP: 343-368 In: M. G. Klotz (Ed.). Methods in Enzymology. Vol. 486. Research on Nitrification and Related Processes, Part A. Academic Press (Elsevier Inc.), Oxford.

34. Pihlatie, M., E. Syväsalo, A. Simojoki, M. Esala and K. Regina. 2004. Contribution of nitrification and denitrification to $\mathrm{N}_{2} \mathrm{O}$ production in peat, clay and loamy sand soils under different soil moisture conditions. Nutrient Cycling in Agroecosystems 70: 135-141.

35. Price, G. H. 2006. Australian Soil Fertility Manual. $3^{\text {rd }}$ edition. Csiro Publishing. Collingwood, Victoria, Australia.

36. Purchase, B. S. 1974. The influence of phosphate deficiency on nitrification. Plant and Soil 41: 541-547.

37. Riley, J. P. and P. Sinhaseni. 1957. The determination of ammonia and total ionic inorganic nitrogen in sea water. 
Journal of the Marine Biological Association of the United Kingdom 36: 161-168.

38. Robertson, G. P. and P. M. Vitousek. 1981. Nitrification potentials in primary and secondary succession. Ecology 62: 376-386.

39. Robertson, G. P. 1982. Factors regulated nitrification in primary and secondary succession. Ecology 63(5): 15611573.

40. Sahrawat, K. L. 2008. Factors affecting nitrification in soils. Communications in Soil Science and Plant Analysis 39: 1436-1446.

41. Schjønning, P., I. K. Thomsen, P. Moldrup and B. T. Christensen. 2003. Linking soil microbial activity to waterand air-phase contents and diffusivities. Soil Science Society of America Journal 67: 156-165.

42. Schmidt, E. L. and L. W. Belser. 1982. Nitrifying bacteria. PP.1027-1042. In: A. L. Page et al. (Eds.), Methods of Soil Analysis. Part 2. Chemical and microbiological properties. American Society of Agronomy, Madison, WI.

43. Schulten, H. R. and M. Schnitzer. 1998. The chemistry of soil organic nitrogen: a review. Biology and Fertility of Soils 26: 1-15.

44. Seifert, J.1980. Effect of temperature on nitrification intensity in soil. Folia Microbiological 25: 144-147.

45. Sharpley, E. N. 1990. Reaction of fertilizer potassium in soils of differing mineralogy. Soil Science 149(1): 44-51.

46. Shaviv, A. 1988. Control of nitrification rate by increasing ammonium Concentration. Fertilizer Research 17: 177188.

47. Shen, Q. R., W. Ran and Z. H. Cao. 2003. Mechanisms of nitrite accumulation occurring in soil nitrification. Chemosphere 50: 747-753.

48. Singh, B. P. and Z. Rengel. 2007. The role of crop residues in improving soil fertility. PP. 183-214. In: P. Marschner and Zdenko Rengel (Eds.), Nutrient Cycling in Terrestrial Ecosystems. Springer. Berlin, Germany.

49. Smith, R. V., L. C. Burns, R. M. Doyle, S. D. Lennox, B. H. L. Kelso, R.H. Foy and R.J. Stevens.1996. Free ammonia inhibition of nitrification in river sediments leading to nitrite accumulation. Environmental Quality 26(4): 1049-1055.

50. Stark, J. M. 1996. Modeling the temperature response of nitrification. Biogeochemistry 35: 433-445.

51. Stark, J. M. and M. K. Firestone .1995. Mechanisms for soil moisture effects on activity of nitrifying bacteria. Applied and Environmental Microbiology 61(1): 218-221.

52. Tong, D. and R. Xu. 2012. Effects of urea and $\left(\mathrm{NH}_{4}\right)_{2} \mathrm{SO}_{4}$ on nitrification and acidification of Ultisols from Southern China. Journal of Environmental Sciences 24(4): 682-689.

53. Vendrell, P. F. and J. Zupancic. 1990. Determination of soil nitrate by transnitration of salicylic acid. Communications in Soil Science and Plant Analysis 21:1705-1713.

54. Wang, C., S. Wan, X. Xing, L. Zhang and X. Han. 2006. Temperature and soil moisture interactively affected soil net N mineralization in temperate grassland in Northern China. Soil Biology and Biochemistry 38: 1101-1110.

55.Zaman, M. and S. X. Chang. 2004. Substrate type, temperature, and moisture content affect gross and net N mineralization and nitrification rates in agroforestry systems. Biology Fertilizer Soils 39: 269-279.

56. Zhao, W., Z. C. Cai. and Z. H. Xu. 2007. Does ammonium-based N addition influence nitrification and acidification in humid subtropical soils of China? Plant and Soil 297(1-2): 213- 221. 


\title{
Effects of Moisture Conditions and Ammonium Concentration on Nitrification in Two Soils with Different Textures
}

\author{
R. Darabi Kandlaji, SH. Oustan*, N. Aliasgharzad and N. Najafi ${ }^{1}$
}

(Received: June 24-2016 ; Accepted: October 30-2017)

\begin{abstract}
Nitrification is one of the most active biological processes in the soils receiving ammonium nitrogen. The rate of this process is under the influence of several factors and their interactions. In this study, the effects of ammonium concentration and moisture content on the extent of nitrification in two soil samples named A (Loam) and B (Clay loam), which had been taken, respectively, from Marand and Ahar areas, were investigated. A two-week factorial incubation experiment $\left(25 \pm 0.5^{\circ} \mathrm{C}\right)$ was conducted in a completely randomized design with three replications. Factors were urea nitrogen at five levels $\left(0,50,100,200\right.$ and $\left.400 \mathrm{mg} \mathrm{N} \mathrm{kg}^{-1}\right)$, moisture content at three levels $(0.55 \mathrm{FC}-0.60 \mathrm{FC}$, $0.75 \mathrm{FC}-0.80 \mathrm{FC}$ and $0.95 \mathrm{FC}-\mathrm{FC}$ ) and two soil types (A and $\mathrm{B}$ ). At the end of the experiment, concentrations of ammonium and nitrate as well as the values of $\mathrm{pH}$ and $\mathrm{EC}$ were determined. Based on the results, average nitrification at $0.55 \mathrm{FC}-0.60 \mathrm{FC}$ was 22 percent lower than that at $0.95 \mathrm{FC}-\mathrm{FC}$ and no significant difference was observed between $0.75 \mathrm{FC}-0.80 \mathrm{FC}$ and $0.95 \mathrm{FC}-\mathrm{FC}$. Nitrification at the treatment of $400 \mathrm{mg} \mathrm{N} \mathrm{kg}{ }^{-1}$ and $0.55 \mathrm{FC}-0.60 \mathrm{FC}$ was decreased considerably and 25 percent of the added ammonium was accumulated. The average ammonium concentrations did not significantly vary among the levels of 50,100 and $200 \mathrm{mg} \mathrm{N} \mathrm{kg}^{-1}$, but these concentrations were significantly lower than those of $400 \mathrm{mg} \mathrm{N} \mathrm{kg}^{-1}$. Moreover, EC and $\mathrm{pH}$ values of the soils were significantly increased and decreased in response to the nitrification $\left(0.54 \mathrm{dS} \mathrm{m}^{-1}\right.$ and 0.59 at the application level of $200 \mathrm{mg} \mathrm{N} \mathrm{kg}^{-1}$, respectively). On average, the results showed higher nitrification $\left(40.3 \mathrm{mg} \mathrm{N} \mathrm{kg}^{-1}\right)$ in the soil A (Loam texture) than the soil B (Clay loam).
\end{abstract}

Keywords: EC, pH, Nitrification, Soil moisture, Urea

1. Department of Soil Science, College of Agriculture, University of Tabriz, Tabriz, Iran.

*: Corresponding Author, Email: oustan@hotmail.com 